International Journal of

Molecular Sciences

ISSN 1422-0067

www.mdpi.com/journal/ijms

Review

\title{
A Focus on Natural Variation for Abiotic Constraints Response in the Model Species Arabidopsis thaliana
}

\section{Valérie Lefebvre, Seifollah Poormohammad Kiani and Mylène Durand-Tardif *}

INRA/IJPB, Genetics and Plant Breeding Laboratory, UR 254, Route de St Cyr, F-78000 Versailles, France; E-Mails: valefebvre@versailles.inra.fr (V.L.); skiani@versailles.inra.fr (S.P.K.)

* Author to whom correspondence should be addressed; E-Mail: durand-t@versailles.inra.fr (M.D.-T.); Tel. +33-0-130833162; Fax: +33-0-130833319

Received: 16 June 2009; in revised form: 4 August 2009 / Accepted: 11 August 2009 /

Published: 13 August 2009

\begin{abstract}
Plants are particularly subject to environmental stress, as they cannot move from unfavourable surroundings. As a consequence they have to react in situ. In any case, plants have to sense the stress, then the signal has to be transduced to engage the appropriate response. Stress response is effected by regulating genes, by turning on molecular mechanisms to protect the whole organism and its components and/or to repair damage. Reactions vary depending on the type of stress and its intensity, but some are commonly turned on because some responses to different abiotic stresses are shared. In addition, there are multiple ways for plants to respond to environmental stress, depending on the species and life strategy, but also multiple ways within a species depending on plant variety or ecotype. It is regularly accepted that populations of a single species originating from diverse geographic origins and/or that have been subjected to different selective pressure, have evolved retaining the best alleles for completing their life cycle. Therefore, the study of natural variation in response to abiotic stress, can help unravel key genes and alleles for plants to cope with their unfavourable physical and chemical surroundings. This review is focusing on Arabidopsis thaliana which has been largely adopted by the global scientific community as a model organism. Also, tools and data that facilitate investigation of natural variation and abiotic stress encountered in the wild are set out. Characterization of accessions, QTLs detection and cloning of alleles responsible for variation are presented.
\end{abstract}


Keywords: Arabidopsis thaliana; natural variation; QTL; abiotic stress; drought; osmotic stress; cold stress; nutrient deficiency; heavy metal stress; light spectrum

Abbreviations: ABA, Abscisic Acid; Al, Aluminum; BC, Back-Cross; BRZ, Brassinazole; BSA, Bulk-Segregant Analysis; bZIP, Basic region/leucine ZIPper; CBF, C-repeat Binding Factor; Cd, Cadmium; CDPK, Calcium-Dependant Protein Kinase; Col, Columbia; COR, COld Regulated; CRY, Cryptochrom; DRE, Dehydration-Responsive Element; FACE, Free Air Carbon dioxide Enrichment; FR, Far-Red light; GA, Gibberellin; GSH, Glutathione; HKT, High affinity $\mathrm{K}+$ Transporter; K, Potassium; LD, Linkage Disequilibrium; N, Nitrogen; NIL, Nearly Isogenic Line; P, Phosphorous; PAE, Phosphate Acquisition Efficiency; PHY, Phytochrom; QTL, Quantitative Trait Locus; QTN, Quantitative Trait Nucleotide; R, Red light; RIL, Recombinant Inbred Line; ROS, Reactive Oxygen Species; SNP, Single Nucleotide Polymorphism; SOD, Super Oxyde Dismutase; UV, Ultraviolet; WUE, Water Use Efficency

\section{Introduction}

\subsection{Arabidopsis}

Sequencing the genome of Arabidopsis thaliana, the first one completed in plants, was achieved in 2000, bringing new lights on higher plants' genetics [1]. Its small genome (220 Mb on five chromosomes), its short life cycle (2-3 months in the greenhouse) and its large offspring at each generation (more than 10,000 seeds per plant) have made of this small, mostly self-fertilizing Brassicaceae the model plant in molecular genetics, developmental and cell biology. In the last 15 years, large insertion-mutants collections have facilitated the association of a phenotype with the function of a single disrupted gene. More recently, Arabidopsis became an important model species for evolutionary biologists. As almost all selfing species, Arabidopsis plants collected in the wild represent nearly homozygous genotypes which are referred to as accessions. Several investigations have been conducted in the past few years assessing pattern of polymorphism, in order to describe the genetic variability of the species. Ultimately, these studies should reveal the demographic event such as population expansion and/or the involvement of selective events that have shaped populations across the world [2-9]. While demographic events and life history have broad consequences on the whole genome; recombination rate, mutation rate and selection have impact on specific loci [9]. Different molecular methods have been used to investigate population structure: Sequencing of short fragments [5,6,8], typing with microsatellite markers [6], SNPs (Single Nucleotide Polymorphism) [6,9] or more recently high density oligonucleotide arrays [2,3]. These findings revealed a strong population structure in Arabidopsis, displayed by a deviation from the so called neutral model which is defined by a population of constant size, not subjected to any selective neither demographic event. Whereas previous surveys failed due to the lack of data Nordborg et al., using 876 short fragment sequences were one of the firsts to shed some light on population structure in Arabidopsis thaliana [5]. To date, most studies suggest that during the Pleistocene, Arabidopsis may have restricted to one or 
several isolated refugia before expanding in a widespread distribution [10]. However, Schmid et al. ran a survey on 12 accessions sequenced at 334 loci and concluded that population expansion in Arabidopsis is not sufficient to explain the observed patterns of polymorphism [8]. They showed that parameters such as selection should be considered in addition. Recently, a more precise analysis has localized one of the glacial refugia on the Iberian Peninsula [7].

\subsection{Abiotic Stress}

Plants are particularly exposed to stress from their physical environment, as they cannot move away from disadvantageous surroundings and have to cope with the stress on site. An abiotic stress is due to a non-living environmental factor that can have a negative impact on living organisms. Any given environmental factor beyond its normal range of variation, must adversely affect the physiology, development and/or fitness of the plant and will subsequently be referred to as "stress". Regarding abiotic stress, a plant has to deal with the type of stress, the combination of different stresses, which effects can be additive or antagonistic, and the intensity and the duration of stress (Figure 1). Development or growth in such adverse conditions can cause extensive losses to agricultural productions [11]. Depending on these physical parameters, the plant will adjust its phenology and/or growth, then will integrate growth arrest, senescence and meristem protection. The perception of the stress signal will determine its transduction and subsequent physiological responses. Along with primary signals, secondary signals such as hormones, Reactive Oxygen Species (ROS) and $\mathrm{Ca}^{2+}$ cytosolic fluxes are generated [12].

Figure 1. Theoretical graph of the effect of an abiotic stress on plant growth and development.

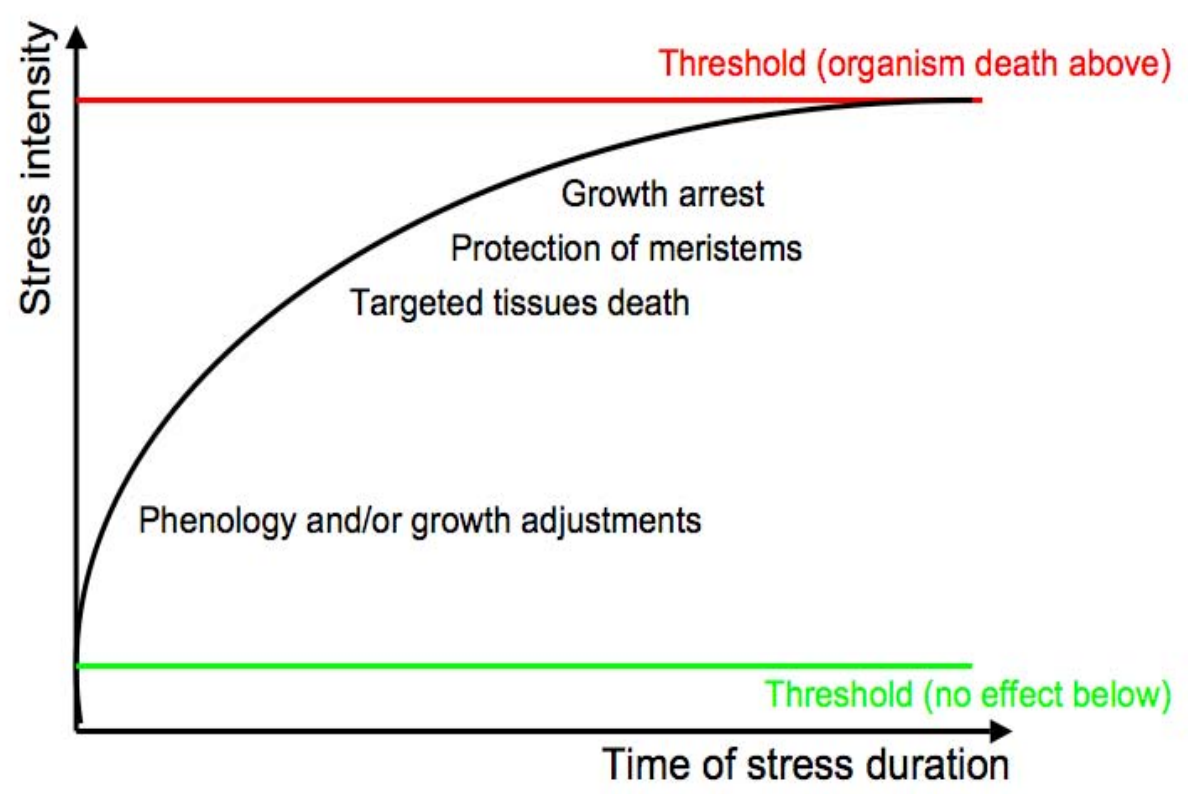

Constraints such as drought, light and cold are known to induce the hormone abscisic acid (ABA). The regulation of the ABA-responsive genes occurs through cis-regulatory sequences such as ABRE (ABA-Responsive Element) or DRE (dehydration-responsive element) present in the promoter 
$[12,13]$. The unwanted compounds such as ROS (hydrogen peroxide, hydroxyl radicals, superoxide ions) that plants accumulate in response to an abiotic stress impact the biology of the plant in two ways: either as a secondary signal in different pathways, or through damaging effects in plants due to their cytotoxicity [14]. Therefore their detoxification through the production of antioxydants such as ascorbic acid, glutathione and $\alpha$-tocopherol may lead to stress tolerance [15]. Indeed, overexpressing ROS scavenging enzymes like SuperOxide Dismutase (SOD), Catalase, Glutathione S Transferase, contributes somehow to stress tolerance [16]. Abiotic stresses also elicit "calcium signatures", typified by their amplitude, frequency, duration and subcellular localization [17] that could encode specific signals and responses.

Stress response is effective by turning on molecular mechanisms to protect the whole organism and its components and/or to repair damages. For example, damages in plants can be greatly reduced with the accumulation of compatible osmolytes like proline, which is the major one. This accumulation will decrease osmotic potential in the cytosol and facilitate water uptake, but also has other functions such as protecting proteins from misfolding and overcoming the toxic effect of ROS [18]. Reactions vary depending on the type of stress and its intensity, but some mechanisms are commonly turned on because responses to different abiotic stress in plants share common steps, e.g., the osmotic homeostasis is disturbed in drought or in freezing situations by removal of water and in the presence of salt which acts an osmoticum. In addition, there are multiple ways for plants to respond to environmental stress depending on the species and life strategy. Then, it is not appropriate to qualify a genotype as "resistant" to abiotic stress, the term "resistance" being correct in the case of a pathogen attack, where the biotic challenge mediates a gene-for-gene interaction and a qualitative resistance response (vs sensitivity).

Hence, a plant is able to develop in a wide spectrum of soil conditions, with limitations regarding light, temperature, water status, osmotic potential, nutrients, but also toxic metals accumulated in soils as well as the increase of $\mathrm{CO}_{2}$ in the atmosphere. Recent studies have revealed many interactions between stress responses. These cross-talks can take place at different levels such as hormonal signalling and reception or transgression of the signals [19].

Many aspects of regulatory mechanisms or signalling pathways may not be revealed through mutants' studies, partly due to gene redundancy or epistatic interactions. Thus, natural variation and quantitative genetics are promising alternative to detect new functions and genes. The accessions of Arabidopsis have each developed adaptive strategies to cope with their potentially deleterious natural environment. It is regularly admitted that populations of a single species originating from diverse geographic origins and/or that have been submitted to different selective pressure, have evolved retaining the best alleles for completing their life cycle. Therefore the study of natural variation in response to abiotic stress, can help to unravel key genes and alleles for plants to cope with their unfavourable physical and chemical surroundings.

It seems rational to observe the extent of a trait variation before studying its genetic support. Natural variation has been assessed for numerous traits in Arabidopsis. This is straightforward for simple characters: as long as the environmental conditions are homogeneous in the experimental system, one can quite easily assess flowering time or biometric parameters. When it comes to stress response one should precisely control stress strength and apply it homogeneously over the experimental system. This requires precise climatic control and homogenization of the physical 
constraints over the culture space. Greenhouses conditions are quite homogeneous but one cannot reproduce the climatic conditions over the time, which is a problem when studying complex characters. Growth chambers appear as a good alternative to control tightly temperature, light intensity and hygrometry. Even if the quality of the climate control has significantly improved lately, it often remains heterogeneous at the plant scale. Technical solutions have emerged recently to get more and more homogenized culture conditions. Culture robots that continuously move the plants across all positions over a culture space for a given culture cycle are worthwhile as they ensure that all the individual plants perceive the same conditions of light, temperature and humidity on average over the experiment. That type of robots has been set up for crops by private companies (Cropdesign, LemnaTec...). At INRA in Versailles, a so-called Phenoscope devoted to Arabidopsis is under proofof-concept phase (Figure 2).

It is trivial to point out that the results we get of a screen for stress response depend on the traits measured. Therefore, the choice of the trait is crucial. It should be a compromise between an integrative trait that reflects the overall physiological state of the plant (e.g., the rosette surface in Arabidopsis [20]) and a trait that reflects a specific aspect of a particular stress response (e.g., the electrolyte leakage, often measured in response to freezing, reflects damages to the membranes [21]). The trait measured is giving one objective insight of the plant response to stress but is not prefiguring stress tolerance "in the field" because of the complexity of the stress themselves and the complexity of the plant response to stress.

Figure 2. Phenoscope: this Arabidopsis culture system created at INRA-IJPB Versailles is able to grow and move 735 plants over the culture table, to adjust their water and nutrient status individually and to monitor their growth by image analysis.

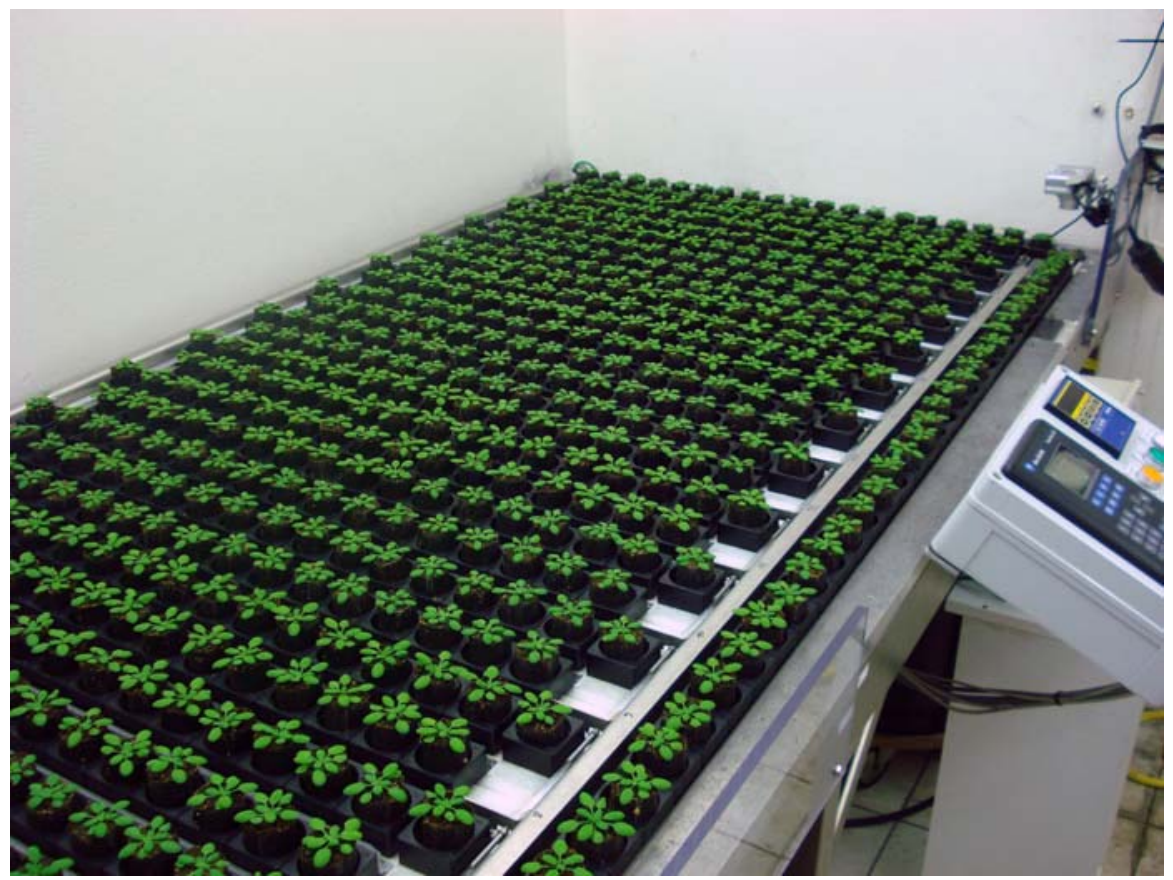




\subsection{Natural Variation}

There are two ways to exploit natural variation. One is to seek a common signature among accessions in response to stress, in order to point out a common general mechanism. A large number of characterized accessions coupled with a high density molecular marker map allow the establishment of a correlation between genotype and phenotype. Another is to look for differences among accessions to foresee trait segregation that could be studied in dedicated cross. A continuous range of phenotypes is obtained in segregating populations derived from crosses between two accessions due to different allelic combinations driving the phenotype, combined with environmental effect [22]. Traits that are distributed continuously are referred to as quantitative and the associated genomic regions are called Quantitative Trait Loci (QTLs). QTLs could be analyzed using family-based mapping populations such as F2, Back-Cross (BC) and Recombinant Inbred Lines (RILs), or natural independent populations in Linkage Disequilibrium (LD) mapping or association mapping studies. QTL analysis aims to:

1) Determine the number and position of loci controlling a trait;

2) Estimate the effects and the mode of action of individual QTL;

3) Detect the epistatic interactions among QTLs;

4) Detect QTL by environment interactions (QTLs affecting plasticity);

5) Detect putative pleiotropic effects of QTLs on various traits in the same mapping population.

The main objective of QTL mapping is the identification of sequence change that underlies a specific variant phenotype and the analysis of the causal gene's responsible for the variation. The identification of a sequence polymorphism that causes natural variation requires laborious cloning approaches [23]. First, a fine mapping is required to reduce the region containing the QTL and subsequently decrease the number of candidate genes. Then, functional genomic strategies would be used to find the precise gene and the nucleotide polymorphisms affecting the function (reviewed in $[4,24,25])$.

In the present review, abiotic stress commonly encountered by plants in the wild will be reviewed. Each abiotic factor will be characterised, then response variation among Arabidopsis accessions will be described and the state-of-art for QTL detection and cloning will be analysed. The involvement of epigenetics variation in response to stress is not included in this review.

\section{Salt, Drought and Osmotic Potential}

Water availability is quite obviously a significant selective agent within natural plant populations. Understanding the genetic and physiological basis of drought adaptation is therefore important for understanding the evolution of wild species as well as for improving crop plants.

Arabidopsis, like other annual plants, cope with drought by using three types of adaptive strategies:

1) Drought escape, that allows plant to reproduce and leave an offspring before the environment becomes dry, probably as a life strategy (for review, see Chaves [26]).

2) Dehydration avoidance refers to growth adjustment in order to avoid internal physiological perturbations. Under drought, plants close their stomata to save water and lengthen their roots to reach more water. For most plants, dehydration avoidance is achieved primarily through the regulation of 
stomatal conductance in order to maintain the internal water status of the plant [27]. However, as stomata are also used in respiration, plants under drought stress need to find a balance in order to maintain a residual carbon assimilation and subsequent growth. This can be measured as the Water Use Efficiency (WUE), the amount of carbon gained per unit water consumed [28].

3) Dehydration tolerance that varies with the genotype is the ability to endure tissue dehydration, sometimes through the accumulation of metabolites, in order to save the whole organism.

These classes are quite theoretical: plants experience such a variety of combined and stochastic stress that responses are complex and mixed.

Natural variation has poorly been exploited to identify new genes or alleles responsible for water deficit tolerance, probably underlying the complexity of this stress. Pigliucci et al. studied four accessions, Greenville (GRE), Turk Lane (Tul), Kendalville (Ken) and Landsberg erecta (Ler) in response to different water supplies [29]. Four biometric parameters out of nine showed significant genetic variation among accessions, but no interaction was found, meaning that these accessions react the same way to applied treatments. Meyre et al. compared the Ler and Col accessions as well as their reciprocal F1 progeny, for a series of biometric parameters and ABA content in response to water deprivation [30]. Most of the measured traits were different among the parents and display a dominant inheritance and hybrid vigor. McKay et al. did not apply a so called water stress but examined 39 accessions for their WUE [31]. They used the isotopic discrimination against the heavy carbon isotope ${ }^{13} \mathrm{C}$ during photosynthesis or " $\Delta{ }^{13} \mathrm{C}$ " to assess the WUE [32]. They observed variation for this trait and a correlation with flowering time. These results confirmed that Arabidopsis natural accessions have different strategies to cope with water availability. Nine accessions have been observed for their response to controlled soil water deficit by Granier et al. [33]. An-1 shows a noteworthy behaviour, as its final leaf area increases and its transpiration rate per unit of leaf area is maintained with the diminishing soil water content. Bouchabke et al. went further, studying four physiological and biometric traits on 24 accessions [34]. They found substantial variation in response to drought: Every trait shows a significant accession $\times$ treatment interaction. A Principal Component Analysis revealed that the Cvi-0 and Shahdara accessions are outliers and interesting genotypes to study drought response.

Hausmann et al. evaluated the genetic architecture of drought-related traits and their plasticity in response to water stress in Ler $\times \mathrm{Col}$ and Ler $\times$ Cvi RILs populations [35]. Flowering time, number of rosette leaves and lateral branches, shoot and root biomass and final number of fruits were studied under well-watered and water-stressed conditions. The majority of traits were controlled by three or fewer QTLs in both populations and some traits such as shoot biomass, fitness and rosette area were influenced by only one QTL in Cvi $\times$ Ler population. For the drought-avoidance mechanism, WUE assessed as $\Delta^{13} \mathrm{C}$, four QTLs were identified in Cvi $\times$ Ler population and two QTLs were found in $\mathrm{Col} \times$ Ler population. Ler alleles increased WUE as compared to Col and Cvi accessions. The authors reported only two QTLs which control both $\Delta^{13} \mathrm{C}$ and shoot biomass and no QTL were co-located between $\Delta^{13} \mathrm{C}$ and fruit production, which are not genetically correlated in this case. Two trade-off QTLs were observed between $\Delta \Delta^{13} \mathrm{C}$ and tissue percent nitrogen as well as between $\Delta{ }^{13} \mathrm{C}$ and branch production indicating the inability of plants to maintain simultaneously high photosynthetic area and high WUE. Interestingly, most traits showed significant phenotypic plasticity as well as QTL $\times$ environment interaction and some of the interactions were environmentally dependent. This 
reveals the complexity of water stress tolerance. In this study, an epistatic interacting QTL was mapped for both branch number and flowering time that had been already detected by Ungerer et al. [36]. These results showed that not only QTL location but also some interactions could be consistent across environments.

QTL mapping for flowering time (a drought escape mechanism) and $\Delta^{13} \mathrm{C}$ (a drought-avoidance mechanism) has been also reported in Ler $\times$ Cvi population [37]. Ten genomic regions were observed for these traits and three of the $\Delta^{13} \mathrm{C}$ QTLs detected in this study were previously identified in similar conditions [35]. Interestingly, two $\Delta^{13} \mathrm{C}$ QTLs were located within the genomic position of flowering time QTL which indicated a functional or pleiotropic relationship between these traits. The authors developed Near Isogenic Lines (NILs) containing Cvi and Ler alleles. NILs segregates at the target locus but identical elsewhere. Cvi alleles at two $\Delta^{13} \mathrm{C}$ QTLs showed increased stomatal conductance and water loss rate, and decreased transpiration efficiency. NILs analysis suggest that genes underlying the observed physiological effects play important roles in controlling stomatal closure during leaf dehydration as well as gas exchange under well-watered conditions.

In other mapping populations, McKay et al. analyzed two reciprocal crosses between Kas-1 and Tsu-1 as these accessions are supposedly coming from dry (India) and wet (Japan) areas, respectively, and show extreme opposite WUE [38]. Two genomic QTLs, assessed by $\Delta^{13} \mathrm{C}$ measurement were localized for WUE, the Kas-1 alleles giving a higher WUE. In addition a cytoplasmic component was detected with an inverse effect: Kas-1 cytoplasm giving a lower WUE. This tends to show opposite selective force driving on the nuclear and cytoplasmic compartments for water economy and overall metabolism.

In 2005, Masle et al. published the results of a QTL detection for transpiration efficiency $\left(\Delta^{13} \mathrm{C}\right)$ in a Col $\times$ Ler mapping population [39]. The causal gene has been identified as the ERECTA gene that has also been described for its role in patterning tissues in stems and pedicels. By studying mutants and transformed lines, Masle et al. showed that ERECTA is also involved in transpiration efficiency, leaf development and gas exchange in well-watered or in drought environment.

Salt stress, like low temperature is often accompanied by dehydration and osmotic stress. The accompanied low osmotic potential hence reduces water uptake by the plant, resulting in "physiological drought". The root system shows indeterminate growth and assures two main functions: The anchorage to the soil and the exploration thereof for water and minerals. It is regularly admitted that osmotic potential of the soil has great consequences on the root system architecture. Deak and Malamy have indeed shown a reduction of the root system apparatus when growing plants on osmoticum, due to the repression of lateral root formation [40]. Fitz Gerald et al. investigated osmotic stress response of RILs from a Ler $\times$ Col cross, as Ler has a significantly higher total lateral roots length value than Col on medium supplemented with mannitol [41]. Two QTLs confirmed with NILs were identified: EDG1 and EDG2 (Elicitors of Drought Growth), which have an effect through the regulation of lateral root primordia activity. The Col root system shows weaker performances on osmotic medium, but unexpectedly, the $\mathrm{EDG}^{\mathrm{Col}}$ allele promotes the overall root system size.

Salt stress also inhibits plant growth through toxicity, as a result of ion-excess inside the plant [42]. Generally speaking, the acclimation phenomenon allows plants to better endure severe constraints. Hence, plants can become more resistant to salt with a period of acclimation, i.e., an exposure to low salt concentrations [43]. 
Natural variation for $\mathrm{NaCl}$ tolerance was observed among 102 accessions of Arabidopsis and the cross Ler-0 $\times$ Col-4 was utilized for mapping the underlying QTLs and candidate genes [44]. These authors showed that $\mathrm{NaCl}$ tolerance in this cross is a polygenic trait. Their results also demonstrate that genetic control of $\mathrm{NaCl}$ tolerance at germination and vegetative growth stages are independent and they detected five QTLs for each of these traits, both parental lines contributing in positive alleles. The authors found that some of the QTLs identified in their study are mapped close to genes involved in ABA response (ABscisic Acid Insensitive 1 (ABI1), ABI2, and ABI3), ABA biosynthesis (ABA3) or ABA modulation (ABA Hypersensitive $1(A B H 1)$ ). Some candidate genes involved in other environmental responses such as drought (dehydration-responsive genes $R D 26, R D 29 A, R D 29 B$, and Dehydration-Responsive Element Binding Protein DREB1) or freezing response (SFR5) were also located on the QTLs for $\mathrm{NaCl}$ tolerance. Another significant localization was the map position of a QTL involved in the variation in fresh weight. Liu et al. showed its co-localization with SOS2 gene, whose product is a Ser/Thr protein kinase required for salt tolerance during vegetative growth in Arabidopsis [45].

Rus et al. used natural variation to identify a new AtHKT1 allele responsible for elevated $\mathrm{Na}^{+}$ accumulation in the shoots, which is also associated with $\mathrm{NaCl}$ tolerance in Arabidopsis [46]. The authors coupled high-throughput elemental profiling with genetics and DNA microarray-based mapping techniques. Analysis of shoot tissue from different Arabidopsis accessions revealed that Ts-1 and Tsu-1 collected from geographically distinct populations, respectively coastal regions of Spain and Japan, accumulated higher levels of $\mathrm{Na}^{+}$. The cross between each accession (Ts-1 and Tsu-1) and Col-0 showed that high $\mathrm{Na}^{+}$phenotype segregates as a monogenic recessive trait. A candidate gene, AtHKT1, which had been previously described as a $\mathrm{Na}^{+}$transporter was found among the two loci identified [47-49]. Complementation tests with a T-DNA insertional null mutant hkt1-1 establishes that alleles present in Ts- 1 and Tsu- 1 are responsible for elevated $\mathrm{Na}^{+}$accumulation. An interesting output of this work is that, comparing with a mutant line sensitive to $\mathrm{NaCl}$ because of over-accumulation of $\mathrm{Na}^{+}$in shoots, the accumulation of $\mathrm{Na}^{+}$in the shoot of Ts- 1 and Tsu- 1 does not cause increased sensitivity to $\mathrm{NaCl}$ [47,50]. Further analysis of a $\mathrm{F} 2$ population derived from Tsu- $1 \times$ Col- 0 cross showed that the allele of Tsu-1, conferring $\mathrm{Na}^{+}$accumulation, co-segregates with enhanced $\mathrm{NaCl}$ tolerance as the homozygous plants for Tsu-1 alleles are able to survive longer in the presence of $100 \mathrm{mM} \mathrm{NaCl}$. The evidence confirmed previous results obtained in Arabidopsis: Reduced shoot accumulation of $\mathrm{Na}^{+}$is not necessary for enhanced salinity tolerance [51]. This article showed that two accessions collected from geographically and genetically distinct populations [5] could contain the same AtHKT1 allele resulting in the accumulation of $\mathrm{Na}^{+}$as well as higher $\mathrm{NaCl}$ tolerance. However, it should be mentioned that Ostrowski et al. proposed that Japanese accessions might be the result of recent migration/colonization events [6]. The authors proposed an extensive haplotype analyses to identify if this new allele of AtHKT1 has been under recent directional selection before making any conclusive statements about its adaptive significance.

\section{Light}

Light affects all aspects during development and growth of plant. It is one of the four pathways that are involved in the fundamental developmental switch of flowering initiation (for reviews see Komeda 
and Roux et al. [52,53]). The light-dependent pathway involves the perception and integration of changes in photoperiod, light quality and intensity [54]. The major threat concerning light limitation is shading as it limits significantly the quantity of light perceived by the plant, in particular red and blue wavelengths photosyntheticaly active radiations. In response to crowded population, Arabidopsis has developed an adaptive strategy, the shade avoidance syndrome, characterised by elongation of petiols, reduced leaf area and decreased leaf chlorophyll, that would be better designated as "shade escape" as it implies leaving an offspring before the death of the plant [55].

Vascular plants sense light using different photoreceptors specific for different wavelengths: The phytochromes (PHY, red light), cryptochromes (CRY, blue light) and phototropins (UV). Five genes encode phytochrome protein in Arabidopsis, named PHY A to E. They are sensitive to red light (R), far-red light (FR) and more exactly to the R:FR ratio. When subjected to shading, plants are exposed to a low R:FR ratio. PHYA functions as a FR sensor and may be involved in antagonizing shade avoidance. PHYB, PHYD and PHYE act to restrain the shade avoidance phenotypes under high R:FR conditions as phyB mutant displays a constitutive shade avoidance phenotype. The other photoreceptors, CRY1, CRY2 and phototropins mediate hypocotyl elongation in response to reduction in blue light quantity.

Another type of light, ultraviolet (UV) radiation, in particular UV-B, can affect the morphology and development of photosynthetic organisms. An excess of UV-B decreases productivity, degrades DNA, induces oxidative stress, leads to proline accumulation, inhibits photosynthesis and reduces stomatal conductance leading to lower carbon assimilation. It has therefore been suggested that higher tolerance to drought stress in Arabidopsis plants grown under UV-B radiation could be attributed to the decreased stomatal conductance and increased proline content [56].

The light responses of natural populations and species native of different habitats potentially harbors adaptive variation; therefore understanding the mechanisms underlying photomorphogenic variation is of significant interest [57]. Arabidopsis thaliana wild strains grow across a wide range of latitudes, with large differences in light quality, intensity and photoperiod. Response to light has been studied in different accessions. In 1995, Pigliucci et al. showed that plain or shaded sunlight generates different response among four accessions, for three traits representing plant growth and size and one trait characteristic of reproductive fitness (number of fruits), out of nine measured traits [29]. High quantity of light applied to Ler and Cvi accessions, generates a photooxydative stress. The latter can be enhanced with paraquat, an herbicide that causes a light-dependent increase of superoxide radical. In this study Cvi showed a higher rate of stress survival, of chlorophyll and of SOD activity; the higher tolerance of Cvi to light stress is assumed to be caused by an enhanced superoxyde radical detoxification [58].

Light quality received by plants is diverse. Maloof et al. studied the response of 141 Arabidopsis accessions from around the Northern hemisphere, in five different light conditions: White, blue, red, far-red light and dark [59]. The hypocotyl length was measured as an indicator of response to light. Indeed, after germination the hypocotyl develops until light triggers the transition phase from heterotrophic to phototrophic, stopping hypocotyls elongation, unfolding cotyledons and beginning chloroplasts development. Significant different responses to light were observed and a mild correlation between light response and latitude of origin was detected, in the way that accessions from lower latitudes are less responsive, probably to compensate higher light exposure. 
A high FR:R light ratio may be considered as a mimicry of high density plant population and shading because selective radiation absorption by the pigments causes reflection enriched in the FR wave-band. Botto and Smith studied 157 accessions, measuring "days to bolting" and "number of leaves to bolting" as indicators of the precocity of flowering and "hypocotyl elongation", as indicator of elongation response. The three traits showed extensive variation. The median of the "number of leaves to bolting" is divided by four from white light (no FR signal) to high FR signal suggesting that the response is varying with increased FR light intensity. It is worth mentioning that variation for precocity of flowering and for hypocotyl elongation are not correlated. The authors pointed out candidate accessions for quantitative genetic analysis: Bla-1, Bla-6, Co-4, Ge-2, Lu-1 and Sf-2 because of their unusual weak response to FR [55].

De-etiolation is initiated by red, far-red and blue light and perceived by the plant through photoreceptors (for recent review see Bae and Choi [60]). As the FR pulses induce weak responses, this is a way to explore the genetic control of sensitivity to light. The response of Ler and Cvi to de-etiolation by FR light pulses are different [61]. Under R pulses only the hypocotyl length witnesses a different response for the two accessions. Magliano et al. reported the characterization of 52 Arabidopsis accessions in response to FR pulses. They measured hypocotyls length and angle between cotyledons as an indicator of cotyledons unfolding. Most of the accessions show a weak response to FR pulses and the two traits are not correlated. Forty accessions among 52 showed reduced cotyledons unfolding suggesting that this character is commonly repressed in populations [62].

Natural variation regarding response to UV-B has a potential interest in the context of stratospheric ozone reduction which is linked to increased UV-B radiation on Earth. Torabinejad and Caldwell have studied UV-B radiation on seven Arabidopsis accessions originating from seven similar environments (100 $\mathrm{m}$ above sea level, $3^{\circ}$ latitude) [63]. All measured biometric traits showed a genotype effect. A treatment effect as well as a genotype $\times$ treatment interaction was observed, except for the shoot architecture parameters. Because the accessions are coming from populations that are not supposed to be exposed to different UV radiation, the results might reflect the intrinsic variation for UV-B tolerance. The mechanisms underlying this tolerance might have other selective functions, like tolerance to other biotic or abiotic stress. Cooley et al. studied seven accessions from diverse geographic origin [64]. They observed response to UV-A as well as to combined UV-A + B. Nine biometric traits were measured and three parameters were derived out of these traits. Once subjected to UV-A or UV-A + B, most of the time, inhibitory responses were found. The accessions with the highest growth rate exhibited the highest growth rate inhibition by UV-B + A as illustrated by the linear correlation for these two traits. The only exception is the Aa- 0 accession, where most of the traits were unexpectedly promoted by UV-A.

As previously mentioned, plants use different photoreceptors to survey their light environment. Natural variation in light response of Arabidopsis has been extensively studied and the causal polymorphism of several light-responsive traits such as seedling emergence or hypocotyls elongation $[57,59,65,66]$ and flowering time $[65,67-69]$ were displayed using natural variation studies.

El-Assal et al. described the genetic basis of natural variation for flowering response to photoperiod using QTL map-based cloning [67]. A QTL (named Early Day-length Insensitive, EDI) for flowering response to photoperiod has been identified in a Ler $\times$ Cvi mapping population. Positional cloning followed by transgenic complementation and sequence analysis revealed that the mutation responsible 
for EDI is a novel allele of CRY2 which had previously been shown to promote flowering in long day photoperiods [70]. A methionine at position 367 of CRY2 in Cvi instead of valine in Ler, is the molecular basis of differences in flowering phenotype. This valine residue is highly conserved across plant CRY proteins. The substitution creates a dominant gain-of-function allele which is likely to be sufficient to explain the difference in response to photoperiod between Ler and Cvi accessions. Interestingly, an exploration of the valine to methionine substitution, among different Arabidopsis accessions showed that this allele is very rare and specific to Cvi; its ecological significance being unclear.

Genetic variation between Ler and Cvi has been widely used for analysis of light responses in Arabidopsis. One hundred and five RILs from crosses between Ler and Cvi were used to investigate the regulation of sensitivity to light signals perceived by phytochromes in etiolated seedlings [61]. Three QTLs were identified for hypocotyl growth inhibition and three QTLs (including VLF6) were identified for cotyledon unfolding under FR light. Fine mapping and transgenic complementation using material developed initially for flowering time QTL showed that the VLF6 QTL is explained by the Cvi allele of CRY2, responsible for enhanced cotyledon unfolding under FR pulses. The authors concluded that the blue light photoreceptor CRY2 can modulate seedling photomorphogenesis in the absence of blue light. Interestingly, cytoplasmic effects on seedling de-etiolation were also identified.

QTLs for light response in RILs population generated from $\mathrm{Col} \times \mathrm{Kashmir}$ crosses were identified by measuring seedling hypocotyl length in blue, R, FR, white light and in darkness [71]. From eight QTLs identified, five localized near photoreceptor loci. Two QTLs detected in blue light were associated with CRY1 and CRY2, and two QTLs in R light were near PHYB and PHYC and finally one QTL in FR was localized near PHYA.

It is worth mentioning here that one accession, Lm-2, showed similar responses to light conditions as phya mutants, causing reduced FR sensitivity [59]. Sequence comparisons showed that a highly conserved amino acid in the PHYA protein is substituted from methionine to threonine (M548W) in Lm-2 and is responsible for the observed phenotype.

More recently, Balasubramanian et al. revealed that a $\mathrm{R}$ receptor PHYC controls natural variation for both flowering time and hypocotyl elongation [65]. First, a QTL for flowering time in a Fr-2 $\times$ Col-0 population has been identified in the PHYC region. A change in the first exon of the PHYC gene converting the L299 to a stop codon gives rise to a truncated protein lacking several essential functional domains and is related to the phenotypic variation for flowering time. Results showed that PHYC also accounts for variation in hypocotyl length of 115 wild strains that have been previously investigated by Maloof et al. for their response to different light conditions [59]. In addition, PHYC sequence was shown to be more divergent than those of other phytochrome genes in Arabidopsis, this gene being potentially under adaptive selection and its contribution to flowering time being latitude-dependent [65].

Filiault et al. investigated the involvement of another receptor for R in light sensitivity, PHYB, by sequencing this gene in 140 accessions that have been previously phenotyped for light response of hypocotyls elongation [57,59]. An association mapping and regression analysis revealed one polymorphism as the cause of variation among accessions. Polymorphism in PHYA and CRY2, as described above, are limited to individual accessions [59,67], making it difficult to know whether they confer adaptation or not to environment. In contrast, alternative variants that cause differential light 
sensitivity are more common in the case of PHYC and PHYB, suggesting that they may be important in adaptation $[57,65]$.

The role of hormones in light response has also been studied. DELLA proteins, growth repressors involved in gibberellins signalling, were shown to play a central role in the shade avoidance response, as their degradation increased in canopy-grown plants. This process is suggested to be driven through multiple photoreceptors interplay (for review see [72]). Brassinosteroids are involved in light response as they suppress photomorphogenic growth in the dark [73].

QTLs responsible for natural variation in light and hormone response between the Cvi and Ler accessions were also identified using 150 RILs [25]. Hypocotyl length was measured in four light environments: White, blue, R, and FR light and in the dark. In addition, white light plus gibberellin (GA) and dark plus brassinazole (BRZ, a brassinosteroid biosynthesis inhibitor) were used to detect hormone effects. Twelve new QTLs, as well as loci harboring known candidate genes were identified. Results showed both environment-nonspecific QTLs and QTL $\times$ environment interactions. A major QTL, LIGHT1, maps to an unknown locus with effects in all light environments. In this study, the known erecta mutation has been shown to explain the effect of the HYP2 QTL in the blue, BRZ and dark environments, but not in FR. Another QTL, LIGHT2, with effects in white and R light shows interaction with GA and could be the photoreceptor PHYB.

Magliano et al. detected a QTL that accounts for the longer hypocotyl in No-0 compared to Ler under different light or dark conditions in the Ler $\times$ No-0 population [62]. This QTL collocates with HYP2, previously mapped using Ler $\times$ Cvi RILs [61,74]. A QTL that enhanced cotyledon unfolding in Ler compared to No-0 under continuous FR (UNF1) was also mapped.

More recently Loudet et al. described one major QTL (LIGHT5) and its underlying zinc knuckle/PLU3 domain encoding gene (TZP) involved in natural variation for hypocotyl elongation response to light [66]. LIGHT5 was detected and fine-mapped on chromosome 5, in Bay-0 $\times$ Shahdara derived populations, down to three candidate genes. The authors showed that an 8-bp insertion in TZP causes a stop codon in Bay-0, which is sufficient to explain LIGHT5 phenotype. The Shahdara allele increases hypocotyl length. Further genomic analysis showed that this gene is unique and acts downstream of the circadian clock and photoreceptor signalling pathways, regulating blue light-dependent morning-specific growth. However the impact of this gene in adaptation is not yet clear.

\section{Temperature}

The effect of temperature varies extensively, from freezing to hot. Little is known about the molecular basis of the natural variation for freezing tolerance; although cold and freezing conditions are two relevant factors limiting the distribution of plant species. The acclimation phenomenon i.e., exposure to cold or sub-zero temperatures, makes it particular as it conditions the tolerance to freezing temperature [75]. Cold stress results in changing gene expression and membrane lipid composition, accumulation of compatible osmolytes, ABA transient elevation and diminution of plant growth [76]. One example would be the eskimo1 mutant, described as cold-tolerant by Xin and Browse, which shows an increased proline accumulation [77,78]. Bouchabke-Coussa et al. later confirmed that 
eskimo1 mutants indeed exhibited higher cold tolerance than the wild type only when exposed to freezing after acclimation [79].

It is admitted that freezing generates an osmotic and a mechanical stress due to ice crystallization. Low temperature also imposes a dehydration stress by lowering water absorption by the root and water transport in the shoot [80]. Indeed, freezing temperature may prevent sufficient water uptake due to progressive solidification of the apoplast which consequently causes reduction of the water potential [13]. Le et al. proved that only the sensing of temperature is responsible for sub-zero acclimation as it can be achieved even if water crystallization is avoided [81].

Moreover, Soitamo et al. shed light into the necessity of light for induction of some cold responsive genes, in particular the CBFs. CBFs or C-repeat Binding Factor also called DREB1 for DehydrationResponsive Element Binding Factor are transcription factors induced by cold and water stresses. They also showed an increase in the production of ROS and the up-regulation of certain genes encoding ROS scavenging proteins under these conditions [82].

Le et al. characterized four accessions for their cold and freezing acclimation capacity measuring electrolyte leakage and deducing a Leakage Temperature $50\left(\mathrm{LT}_{50}\right)$ : A temperature where $50 \%$ of electrolyte leakage occurred [81]. They have shown a great variation in the sub-zero acclimation depending on the temperature and the time of exposure. There is no correlation between cold and freezing acclimation capacity suggesting their genetically independent basis. This was in accordance with another study showing that the Col accession is more freezing tolerant than $\mathrm{C} 24$, with or without acclimation [83]. Hasdai et al. showed that observing growth parameters on accessions at $6{ }^{\circ} \mathrm{C}$ and $14{ }^{\circ} \mathrm{C}$ could not be used to predict tolerance to freezing [84]. Zhen and Ungerer observed considerable differences in freezing tolerance among 71 accessions that showed a clinal pattern with latitude of origin, with or without acclimation [85]. The authors suggest that inducible cold response has a cost which might be counterselected in geographical zone that are not likely to experience freezing stress. Additional experiments are needed to confirm this hypothesis. McKhann et al. also show important variation for tolerance to $-5{ }^{\circ} \mathrm{C}$ exposure after acclimation [86]. They reinforced the fact that freezing tolerance is a complex character showing that CBF and COR (COld Regulated) genes respond differently to stress among eight accessions, though there is no clear correlation between gene expression, sequence polymorphism and freezing tolerance. Thereby, freezing tolerance is complex and $C B F$ genes by themselves cannot explain the phenotypic variation. Global transcript and metabolite profiles have been observed by Hannah et al. on nine accessions subjected to freezing with or without acclimation [87]. They observed considerable variation and a significant correlation between freezing tolerance and accessions' habitat of origin. They also demonstrated that accessions that are able to acclimate showed a 1.5- to 2-fold changes in global gene expression compared to non-acclimated plants. Moreover, no clear relationship has been found between metabolite changes and acclimation capacity. Swindell et al. studied gene expression patterns in response to cold $\left(4{ }^{\circ} \mathrm{C}\right)$ and to heat $\left(38{ }^{\circ} \mathrm{C}\right)$. About $70 \%$ of the genes are responding to stress but only 43 of them are considered as adaptive, i.e., their expression level co-vary with the average temperatures in the geographic origins of the accessions [88]. Another study relates the effect of chronic low-temperature on biometric parameters and gene expression among 23 accessions [89]. Variation is observed for root elongation rate at ambient and at low temperature but except for Er-0, all the accessions respond the same way. 
Several studies have been conducted to assess the flowering time in response to ambient temperature variations, like $16^{\circ} \mathrm{C}$ and $25^{\circ} \mathrm{C}[65,90,91]$, which do not constitute a stress per se as only two stress responsive genes were induced at $25{ }^{\circ} \mathrm{C}$. Results showed that a slight temperature variation can induce dramatic effect on flowering time and variation among accessions. An important part of the thermal adjustment is not due to a typical heat shock, vernalization or photoperiodic response, but might reflect a complex genetic network.

Analysis of natural variation leaded to identify $C B F 2$ as a candidate gene for freezing tolerance. Alonso-Blanco et al. identified QTLs controlling freezing tolerance under long day and short day photoperiods: Seven different loci on chromosomes 1, 4, and 5, which were named FREEZING TOLERANCE QTL 1 (FTQ1) to 7, were detected. In all of them, the Ler allele increased freezing tolerance compared to Cvi [92]. Only two QTLs, FTQ4 and FTQ6, were detected in both photoperiod conditions, suggesting that freezing tolerance is also photoperiod-dependent. FTQ4, which showed the larger effect, maps to the region containing a tandem repeat of three highly similar CBF genes (CBF1, CBF2 and CBF3). By sequence analysis the authors showed that the 1.6-kb Cvi deletion in CBF2 promoter region including the ICEr1 (Induction of CBF Expression region 1) sequence and probably other regulatory elements might be the cause of the low cold induction [93]. However, CBF3 also shows a large amount of polymorphisms between Ler and Cvi. The involvement of several genes in FTQ4 is somehow supported by the fact that the three CBF genes do not operate independently [94].

\section{Mineral Nutrition}

Plants must acquire all the mineral nutrients they require for survival, including trace elements, from the complex environment of the soil. Ionomics is a developing functional genomic strategy designed to rapidly identify the genes and gene networks involved in regulating how plants acquire and accumulate these mineral nutrients from the soil [46]. Lahner et al. screened 6,000 fast-neutronmutagenized Arabidopsis plants grown under unstressed conditions, and identified 51 mutants with altered shoot elemental profiles [95]. They estimated that $2 \%$ to $4 \%$ of the Arabidopsis genome is involved in regulating the elemental composition or 'ionomics' [96]. Potentially, all kind of nutrient depletion constitutes an abiotic stress. It is supposed for long that response to nutrient depletion is linked to root plasticity as the larger the root surface is, the better soil exploration would be for nutrients uptake, especially for phosphorus which is an immobile and poorly accessible compound [97].

Phosphorus $(\mathrm{P})$ and nitrogen $(\mathrm{N})$ are the two major nutrients for plant growth [98]. In response to phosphate starvation, which happens notably in acid soils, Arabidopsis plants tend to improve their uptake while increasing root apparatus size. Arabidopsis plants adapt their root architecture in order to improve their uptake: The primary root growth stops and numerous new lateral roots emerge (Reviewed by Raghothama [99]). In addition, numerous root hairs appear, their length being inversely correlated with the $\mathrm{P}$ concentration in the medium [100]. It has long been shown that the phytohormone auxin and the growth regulator ethylene are involved in the modulation of the root architecture via altering primary root growth, promoting root hair and lateral root formation [101]. More recently, the joint action of auxin and ethylene have been related to the modulation of root apparatus in relation to the amount of $\mathrm{P}$ in soil [102]. In acid soils, aluminium and iron will induce $\mathrm{P}$ 
deficiency, due to the formation of insoluble complexes unavailable for plant uptake. On the contrary, in alkaline soils, P bounds magnesium or calcium and forms weakly soluble compounds [103]. In order to cope with P-limiting conditions, plants increase excretion of organic acids like citrate, whose high affinity for cations will displace $\mathrm{P}$ from their insoluble complexes, making it available for plant uptake [104].

Arabidopsis has also developed adaptive responses to N-limited soils: Increased root growth, photosynthesis reduction, $\mathrm{N}$ remobilization from older organs leading to senescence and accumulation of protective compounds like anthocyanins. However, the mechanisms of uptake and acclimation to these stress are less documented [105,106].

In 2000, Narang et al. deeply analyzed five accessions for their root morphology and phosphate uptake parameters in response to phosphate depletion [107]. Three of them (C24, Co and Cal) showed a high Phosphate Acquisition Efficiency (PAE), the other two (Col-0 and Te), showed a lower PAE. Meanwhile the efficient accessions display a higher root hair surface on phosphate-free medium. It is tempting to speculate that the two characters are linked. More recently, exploiting a QTL approach, Reymond et al. studied six accessions for their Primary Root Length (PRL) and total lateral root length [108]. The root architecture is already different under standard growth condition and the response to phosphate starvation is even more dramatic, e.g., PRL reduction is of $75 \%$ in Shahdara accession and of approximately $20 \%$ in Bay-0 and Ler. An N:P:K (nitrogen:phosphorus:potassium) gradient has been applied to four accessions resulting in a genotype $\times$ treatment interaction on five out of nine studied traits [29]. Low nutrient has drastic effect on plant traits, ending with smaller plants and lower vegetative growth [109]. A complementary study obtained with 26 accessions under low and high nutrient status, shows a genotype $\times$ treatment interaction, most of the variation being due to a limited number of accessions with highly distinctive phenotypes, the other ones responding similarly to low nutrient treatment [110].

Plants acquire $\mathrm{N}$ from the soil mainly in the form of nitrate. Nitrate limitation has several direct and indirect consequences on growth through modifications of nitrate availability in plant cells and tissues or on osmotic pressure [111]. Loudet et al., presented the genetic analysis of water and anion content variation in the Bay-0 $\times$ Shahdara population of RILs in response to nitrate availability [112]. Water, nitrate, chloride, and phosphate contents were measured at the vegetative stage in the shoots of plants grown in two $\mathrm{N}$ conditions. A total of 34 QTLs were observed for the studied traits. Interestingly, two well-known flowering-time loci, FRI and FLC, were shown to be likely involved in the control of water content variation independently of $\mathrm{N}$ availability. The authors also localized two major QTLs for chloride and phosphate content in limiting $\mathrm{N}$ conditions implemented map-based cloning and showed that they both map on chromosome 1 .

In another publication, Loudet et al. used the same mapping population with the aim of dissecting the $\mathrm{N}$ metabolism pathway in Arabidopsis. They measured shoot growth, total N, nitrate and free amino acids contents in high or low nitrate availability conditions. These traits were significantly correlated in both environments. They identified 48 QTLs in total, mapping at 18 loci at least, most of them being strongly affected by $\mathrm{N}$ limitation in soil. Four to nine QTLs per trait have been found and from none to five QTL $\times$ QTL epistatic interactions, which therefore seem to play an important role in controlling phenotypes. Both positive and negative allelic effects were found. Four loci can be retained as source of major variation in one or both $\mathrm{N}$ environments, which co-localized or not with known 
genes involved in $\mathrm{N}$ metabolism, which demonstrates once again the power of this approach to uncover new genes and pathways [113].

The effect of phosphate deficiency on root development has been studied and a major QTL (LPR1) involved in primary root growth arrest in response to low phosphate and in the control of primary root cell length has been identified in the RILs population derived from the Bay0 $\times$ Shahdara cross [108] The underlying gene, which encodes a MultiCopper Oxidase (MCO) highlights the essential role of MCOs in plant development [114]. LPR1 is differentially expressed in the root cap leading to the modification of the activity and/or the distribution of a hormone-like compound that triggers the primary root development from indeterminate to determinate growth, which consequently reduces cell elongation and promotes lateral roots formation [115].

Sulfur (S) uptake is essential for the biosynthesis of sulfured amino acids, cell metabolism, and stress responses. A decrease in $\mathrm{S}$ uptake can always be linked to many metabolic modifications that strongly change the growth of the plant. Moreover, $\mathrm{S}$ transport and metabolism as been linked to different hormone pathways such as auxin, cytokinins and jasmonic acid [98].

A gene involved in natural variation for sulphate content in relation with $\mathrm{N}$ availability has been described by Loudet et al. [116]. Using a RILs population from the Bay-0 $\times$ Shahdara cross and candidate gene approaches, the authors showed that a gene encoding an adenosine 5'-phosphosulfate reductase (APR2) is involved in sulphate content variation between Bay-0 and Shahdara accessions. An alanine residue changed to glutamate was found to be responsible for sulphate accumulation in the Shahdara accession, because of a reduced APR activity. Interestingly, the Shahdara allelic effect was stronger when $\mathrm{N}$ availability was limitant in soil, confirming the tight relationship between sulphate assimilation and $\mathrm{N}$ metabolism, as an interesting explanation for the QTL $\times$ environment interaction.

Boron (B) is another essential microelement for plant growth and development. B deficiency has been reported to decrease yield in many crop plants [117]. QTLs for B efficiency or tolerance to low B stress, were identified in a 101 RILs population from a Ler $\times$ Col cross, in two separate experiments [118]. Then two RILs that were genotypically and phenotypically different were crossed to further confirm one major QTL, AtBE1-2, as a monogenic locus in the F2 population. The B efficiency coefficient and seed yield under low B conditions were investigated: Five and three QTLs were identified respectively for each trait. Interestingly, some QTLs are common between the two traits. An effort for searching candidate genes showed that ten B-related genes, together with a B transporter homolog (BOR5) were located in the QTL region of AtBE1-2.

Molybdenum (Mo) is also an essential element for living organisms, which, in the form of molybdopterin-cofactor, participates in the active site of enzymes involved in key reactions of carbon, $\mathrm{N}$, and S metabolism [119]. It is notably involved in nitrate assimilation, sulphate detoxification, ABA biosynthesis and purine degradation [120]. Low $\mathrm{pH}$ is a major soil constraint to agricultural production, reducing yield on nearly $25 \%$ of the world's land presently under production and the availability of Mo in acid soils is drastically reduced so that Mo deficiency is a widespread agricultural problem $[121,122]$. For soils above $\mathrm{pH} 4.23$ and those rich in organic matter, the soluble oxyanion, molybdate $\left(\mathrm{MoO}_{4}{ }^{2-}\right)$ becomes the predominant available form [123].

Natural variation has been used in Arabidopsis for understanding the genetic basis of Mo content in plants. Baxter et al. studied natural variation for whole plant Mo content, coupled with QTL based genomic approaches to identify the causal genes [124]. Using a RILs population from the cross 
Ler $\times$ Col-0, the QTL and its underlying gene (MOT1) has been identified. The authors showed that a $53 \mathrm{bp}$ deletion in promoter of MOT1 is strongly associated with low MOT1 expression and low shoot Mo content in Ler-0, Van- 0 and across 92 other accessions. MOT1 belongs to the sulphate transporter superfamily and can specifically transport Mo. It is required for efficient uptake and translocation of Mo, as well as for normal growth under limited Mo supply. This study is an example of how natural variation has been useful to identify a Mo transporter, localized in the mitochondrion, that controls both root and shoot Mo content in Arabidopsis. At the same time, Tomatsu et al. discovered and functionally characterized MOT1 in a Ler-0 $\times$ Col-0 RILs population [125]. These studies provided the first molecular insight into the processes that regulate Mo accumulation in plants.

\section{Metals}

Heavy metals, such as cadmium $(\mathrm{Cd})$, selenium, mercury, etc... are micronutrients essential for plant growth, which can become toxic when present in excess in soil (reviewed by Clemens [126]). Their concentrations in plants are related to their solubility in the soil. It is assumed that only metal ions enter the plant cells and elicit responses to toxicity. These opportunistic ions use cation channels and transporters of low specificity such as those for $\mathrm{Zn}^{2+}, \mathrm{Fe}^{2+}$ and $\mathrm{Ca}^{2+}$. The major site of heavy metal sequestration is the vacuole of root cells, via binding of the ions to glutathione (GSH) or GSH-derived peptide. Else, detoxification may occur from the excretion of organic acids, such as citrate or malate, out of the root tip and their subsequent chelation of metal ions, as it is the most common tolerance mechanism for aluminum $[127,128]$. The symptoms generated by toxic metal ions uptake are mainly side effects. An example would be the water balance disturbance, resulting from the inhibition of stomatal opening caused by metal stress and the subsequent proline accumulation. After $\mathrm{Cd}^{2+}$ exposure, plants present the symptoms of an oxidative stress: This phenomenon is probably due to the binding of $\mathrm{Cd}^{2+}$ to GSH, a ROS scavenging compound (reviewed by Schützendübel and Polle [129]). Noteworthy, the chemical similarity of toxic ions such as $\mathrm{Cd}^{2+}$ with $\mathrm{Ca}^{2+}$ or $\mathrm{Zn}^{2+}$ has strong detrimental consequences on signalling cascades [126].

Genetic analysis of $\mathrm{Cd}$ tolerance has been also reported in Arabidopsis interspecific cross [130]. A. halleri (Cd-tolerant accession) was used to map QTLs and to identify putative candidate genes underlying $\mathrm{Cd}$ tolerance in a first-generation backcross progeny from the cross between $A$. halleri ssp. halleri (pollen donor) and its non-tolerant relative A. lyrata ssp. petraea. The A. halleri genotype was shown to be tolerant to $\mathrm{Cd}$ concentrations and able to hyperaccumulate $\mathrm{Cd}$. 196 individuals of the A. halleri $\times$ A. lyrata ssp. petraea backcross population $(\mathrm{BC} 1)$ was used for QTL mapping and three QTLs on chromosomes 3, 4, and 6 were detected. At all three QTLs, the A. halleri allele had a positive effect on Cd tolerance. The heavy metal transporter gene ATPase4 (HMA4) colocalized with the major QTL and was consequently considered as a candidate gene potentially responsible for the phenotype. Results showed that elevated expression of HMA4 is likely the mechanism for improving $\mathrm{Cd} / \mathrm{Zn}$ tolerance in plants under conditions of $\mathrm{Cd} / \mathrm{Zn}$ excess by maintaining low cellular $\mathrm{Cd}^{2+}$ and $\mathrm{Zn}^{2+}$ concentrations in the cytoplasm.

Rhizotoxicity of aluminum (Al) in acid soil is a major environmental stress [131]. At $\mathrm{pH}$ below 5.5, $\mathrm{Al}^{3+}$ cations are solubilized in the soil solution from aluminosilicate complexes to levels that inhibit root growth and function $[122,131]$. The stunted, poorly functioning root systems that result from $\mathrm{Al}$ 
toxicity directly reduce plant vigour and yield, increasing susceptibility to other stress such as drought and nutrient deficiency. According to Taylor, plants have two types of Al tolerant mechanisms, namely "internal Al tolerance" and "Al exclusion" [132]. Internal Al tolerance is associated with detoxification of $\mathrm{Al}$ in the symplast, such as chelation with organic acids or scavenging Al-induced superoxides through the action of GSH S-transferase $[133,134]$. On the other hand, Al exclusion is associated with detoxification of $\mathrm{Al}$ in the rhizosphere by increasing the $\mathrm{pH}$ of the rhizosphere [135]. Some plants are excreting organic acids to modify the $\mathrm{pH}$ at the root surface [136]. For example, Alactivated root malate release has been reported as an Al tolerance mechanism for Arabidopsis and wheat, and citrate release has been reported for maize Al tolerance [127]. This suggests that higher plants possess a series of Al-tolerant mechanisms in which many Al-tolerant genes would be involved.

$\mathrm{Al}^{3+}$ and $\mathrm{H}^{+}$stresses are linked in field conditions. Ikka et al. studied relative root length on $\mathrm{Al}^{3+}$ and $\mathrm{pH} 4.7$ (excess of $\mathrm{H}^{+}$) hydroponics media relative to standard culture medium, among 260 accessions [137]. They succeeded in differentiating $\mathrm{Al}^{3+}, \mathrm{H}^{+}$and $\mathrm{Al}^{3+}+\mathrm{H}^{+}$combination tolerant accessions (e.g., Lö-2 and Co-4). However no correlation has been observed between $\mathrm{Al}^{3+}$ and low $\mathrm{pH}$ tolerance. Their results indicate that different genetic mechanisms are involved in response to $\mathrm{Al}^{3+}$ and $\mathrm{H}^{+}$.

QTL and epistasis for Arabidopsis Al tolerance were analyzed using a RILs population derived from a cross between Ler and Col [138]. Al tolerance was defined as relative root length of plants grown on $4 \mu \mathrm{M} \mathrm{AlCl}$. Two main QTLs and five independent epistatic interactions were detected. Interestingly, key enzymes related to enhanced organic acid excretion were adjacent to the epistasic loci identified between chromosome 1 and chromosome 3 [139]. Another Al-tolerant gene with an increasing rhizosphere $\mathrm{pH}$ was mapped on chromosome 4, where an epistatic interaction of the relative root length was detected with chromosome 3. Also, an Al sensitive gene was mapped on the chromosome 5, where an epistatic interaction occurs [140,141]. Overexpression of a blue copperbinding protein resulted in enhanced Al tolerance in Ler and a homologue of this protein collocate with an epistatic locus on chromosome 2 [142]. However, a fine-scale mapping is necessary to identify whether or not the epistatic loci and the Al-tolerant genes are identical.

Hoekenga et al. identified two significant QTLs (QTL1 and QTL2) in a Ler $\times$ Col RILs population for Al tolerance estimated as root growth [127]. One of them located on chromosome 1 (QTL1) corresponds to QTL identified previously by Kobayashi and Koyama [138]. These two major QTLs apparently act together in the same pathway, based on evidence for epistasis, and together explain $40 \%$ of the variation in Al tolerance among the RILs. Candidate gene approaches showed that seven Al-inducible genes are located at the QTL1 and eight mapped at QTL2. Thirteen of the fifteen genes have nucleotide differences within the predicted coding sequences or in closely flanking regions in Ler accessions, which may contribute to differences in expression or function between Ler and Col. On the basis of their annotation, three of these genes may encode proteins involved in organic acid transport or metabolism. A malate transporter gene, AtALMT1 (Al-activated Malate Transporter), has also been identified as critical for Al tolerance in Arabidopsis using forward and reverse genetic approaches [143]. However, the location of AtALMT1 on chromosome 1 is not consistent with the major QTLs detected for Al tolerance on the same chromosome in this study. These results suggest that other factors are involved in $\mathrm{Al}$ tolerance and underline the complexity of this trait. 


\section{Carbon Dioxide}

As autotrophic living organisms, plants build their biomass from atmospheric carbon. Actual gradual elevation of atmospheric $\mathrm{CO}_{2}(0,550 \mathrm{mg} / \mathrm{g}$ predicted in 2050 [144]) results in higher growth rate and yield. Indeed, the stomatal aperture is reduced leading to lower evapotranspiration in $\mathrm{C} 3$ and $\mathrm{C} 4$ species. This is part of an acclimation phenomenon. In addition, photosynthesis is enhanced in C3 plants due to an increase in the carboxylation rate mediated by the key enzyme Rubisco (substratelimited at current $\mathrm{CO}_{2}$ concentration) and a reduction of photorespiration (for review, see Ainsworth and Rogers [145]). Elevated $\mathrm{CO}_{2}$ concentration also leads to a decrease in Rubisco quantity in leaves [146] and an increase in the expression of genes related to ROS metabolism and chaperone [147].

In 1995, Zhang and Lechowicz analyzed two accessions, Cvi-0 and Ms-0, in response to $\mathrm{CO}_{2}$ elevation $(\approx 700 \mathrm{ppm})$, at low or high nutrient supply [148]. Among 16 traits, the only significant difference in response to $\mathrm{CO}_{2}$ between the two accessions was observed for the rate of the rosette diameter growth. The results showed that the different sensitivity to nutrient supply does not imply a different sensitivity to $\mathrm{CO}_{2}$. Li et al. used the Free Air Carbon dioxide Enrichment system (FACE) that allows plants grown in the field to be subjected to $\mathrm{CO}_{2}$ increase $(\approx 550 \mathrm{ppm})$ [149]. They tested three accessions and analyzed the metabolite and the transcript profile responses. Among genes varying between ambient and elevated $\mathrm{CO}_{2}$, a large number are involved in metabolic functions. The authors were seeking for a signature across the accessions that could reflect a generalized response to elevated $\mathrm{CO}_{2}$. All signature genes that harbor an annotation have already been reported in response to abiotic stress, according to the hypothesis of Miyazaki that elevated $\mathrm{CO}_{2}$ constitutes a stress per se [150]. Tonsor and Schneider observed 35 accessions under four $\mathrm{CO}_{2}$ concentrations from $250 \mathrm{ppm}$, corresponding to pre-industrial atmosphere to $710 \mathrm{ppm}$ which is the highest projection for the $\mathrm{XXI}^{\mathrm{st}}$ century. A large panel of traits have been measured along plant life-time witnessing growth and phenology, in an attempt to build an explicative model for the observations. The outputs of this study are large. Changes in carbon supply result in plastic positive response on most traits measured, across the gradient. There is a significant "accession effect" on trait variation measured after bolting, consequently a possible effect on fitness, but this study focused on variation across treatments to feed a model. There is a stronger global effect of the lowest $\mathrm{CO}_{2}$ concentration $(250 \mathrm{ppm})$ than the highest (710 ppm), as if the use of excess $\mathrm{CO}_{2}$ was strongly constrained by other parameters, probably water and $\mathrm{N}$ uptake rates [151].

Cross et al. performed a study among 24 accessions under short days, low light and $\mathrm{N}$ excess conditions that are limiting for carbon assimilation and which mimics growth under carbon limiting condition [152]. This is not a stress response study but a good illustration of the great amount of information that can be obtained by studying natural variation under monitored abiotic situations. The authors analyzed the rosette weight as an integrative trait, as well as metabolites and seven enzyme profiles. Results are showing both general features across the accessions like the significant positive correlation between rosette fresh weight and enzyme activities (highest score for aspartate aminotransferase) and divergent strategies carried by some accessions (e.g., the low weight and high enzyme activities of $\mathrm{Pa}-1$ ). The seven enzyme activities involved in central metabolism are positively correlated. There is no overall trend of rosette biomass and metabolites concentration. 


\section{Other Abiotic Stress}

Flooding, waterlodging or even heavy rainfalls saturate the soil with water and induce anoxia that affects root system. One study has been performed with 47 accessions under flooded or non-flooded treatments [153]. Among the nine traits measured, three showed a significant accession $\times$ treatment interaction including root fresh weight.

Oxidative stress can be mimicked with the application of atrazine, a xenobiotic that fixes to the photosystem II, consequently blocking electron transfer and generating ROS. Ramel et al. tested 11 accessions in response to atrazine (manuscript in preparation). They observed large variation in atrazine sensitivity, assessed with biometric and metabolic traits and in ROS accumulation. The authors established correlations between the response to oxidative stress and the endogenous level of soluble sugars.

\section{Conclusions}

This review constitutes an attempt to survey the large and promising possibilities allowed by the study of natural variation and its genetic basis. There is obviously variation in natural population for a range of traits reflecting adaptation to local abiotic environment that is accessible to experimentation with all the necessary care. All these studies report the behaviour of different natural accessions in designed controlled experimental systems, figuring abiotic stress (see Table 1). Thanks to the international effort dedicated to Arabidopsis thaliana, QTL mapping and confirmation is accessible routinely in research laboratories. As listed in Table 2, many QTL related to diverse abiotic constraints have been cloned, using different genetic approaches. Different factors that could greatly contribute to the achievement of QTL detection are listed bolow:

1) The mapping population should be large enough to maximize the recombination events,

2) The studied trait should be easy to screen and show variation among the population lines,

3) Molecular markers should be sufficiently dense on the genome, particularly in the region of interest.

For subsequent cloning, the QTL should explain a substantial proportion of the trait variation to allow its detection in segregating NILs.

Genomic resources like accessions, RILs and sometimes NILs are now available to the global scientific community, like at the Genomic Resource Centre at INRA Versailles (http://dbsgap.versailles.inra.fr/vnat/). The great power of natural variability is also illustrated by the fact that natural alleles can be used to confirm the implication of a gene in a trait (e.g., the complementation of apr-2 mutant with natural allele driving shoot sulfate content [116]. The success story of the natural variation studies in Arabidopsis is due to the implementation of interdisciplinarity between population and quantitative genetics, eco-physiology and all the "omics" techniques at the genome scale. No doubt that in the near future, natural variation studies will keep growing our knowledge of integrated plant response to environmental stress. However, in spite of the increasing interest for quantitative genetics, the discovering of new genes' function can not be split from classical genetics. Mutants' approaches and alleles' complementations will always be the key steps to conclude for the gene underlying a QTL. 
Another available tool that comes from human genetics, might be very useful in the near future to identify genes involved in the variation of quantitative traits. Genome-wide association study or Linkage Desequilibrium (LD) mapping (for reviews see Buckler and Thornsberry and Yu and Buckler $[154,155]$ aims at unravelling the genetic determinism of complex characters making direct use of natural populations, thus exploring the largest genetic basis available in the species. This tool does not need any dedicated segregating population as QTL mapping does. Beside the availability of a population of accessions, one need to genotype and to establish the structure of this population to avoid spurious associations caused by eventual mating restrictions and other effects of population size and dynamics [156]. In Arabidopsis, globally, the linkage disequilibrium is not too extended: Markers around most gene loci rapidly become unlinked. Consequently, the method needs a rather high-but accessible-density genotyping. Until now, the tool was not yet applied to map loci involved in abiotic, but in biotic stress response [157].

As a final point and to stimulate reflection, Fu's et al. brief communication is mentioned: the authors integrated transcript, protein, metabolic and phenotypic data to detect QTLs for 40580 molecular and 139 phenotypic traits [158]. They show that only six loci (5cM window) are merging from $16 \%$ to $77 \%$ of the transcript to the phenotypic variation. This analysis tends to show that, for a given RILs population, major genes are pleiotropic and/or are buffering overall genome variability. This important communication should be taken into account, keeping in mind the huge number of possible cross to scramble together parental genomes and the chance that loci might cover several causal genes.

Table 1. List of studies reporting characterization of Arabidopsis accessions in response to abiotic stress.

\begin{tabular}{|c|c|c|c|}
\hline Accessions $^{1}$ & Stress & Trait & Reference \\
\hline & \multicolumn{3}{|l|}{ Light, Radiations } \\
\hline 4 & $100,80,60$ and $40 \%$ of sun light & Biometric and fitness parameters & {$[29,109]$} \\
\hline 157 & Far-red light ( 3 red/far-red rates) & Flowering time, hypocotyl length & {$[55]$} \\
\hline 141 & White, blue, red, far-red and dark & Hypocotyl length & {$[59]$} \\
\hline 52 & Far-red pulses & $\begin{array}{l}\text { Hypocotyl length, angle between } \\
\text { cotyledons }\end{array}$ & {$[62]$} \\
\hline 7 & UV-B & $\begin{array}{l}\text { Biometric traits on vegetative (2) and } \\
\text { reproductive (4) apparatus. }\end{array}$ & {$[63]$} \\
\hline 7 & UV-A, UV-B + A & $\begin{array}{l}9 \text { biometric traits on vegetative (6), } \\
\text { reproductive ( } 2 \text { ) and root apparatus ( } 1) \\
\text { and } 3 \text { derived parameters. }\end{array}$ & {$[64]$} \\
\hline
\end{tabular}


Table 1. Cont.

\begin{tabular}{|c|c|c|c|}
\hline Accessions $^{1}$ & Stress & Trait & Reference \\
\hline & \multicolumn{3}{|l|}{ Temperature } \\
\hline 21 & 15,20 and $25^{\circ} \mathrm{C}$ & $\begin{array}{l}\text { Flowering time (day of flowering, total } \\
\text { leaf number at flowering), height at } \\
\text { flowering }\end{array}$ & [91] \\
\hline 9 & Cold and freezing acclimation & $\begin{array}{l}\text { Electrolyte leakage, } \mathrm{LT}_{50} \text {, genes and } \\
\text { metabolites expression }\end{array}$ & [87] \\
\hline 4 & Cold and freezing acclimation & $\begin{array}{l}\text { Electrolyte leakage, } \mathrm{LT}_{50} \text {, leaf sugar } \\
\text { content }\end{array}$ & {$[81]$} \\
\hline 71 & $\begin{array}{l}\text { Cold acclimation, sub-zero } \\
\text { temperatures }\end{array}$ & Tissue damage index & {$[85]$} \\
\hline 50 & $\begin{array}{l}\text { Freezing tolerance (with } \\
\text { acclimation) }\end{array}$ & $\begin{array}{l}\text { Tissue damage index, } C B F \text { and } C O R \\
\text { genes expression }\end{array}$ & {$[86]$} \\
\hline 12 & $6{ }^{\circ} \mathrm{C}, 14^{\circ} \mathrm{C}$ and freezing & $\begin{array}{l}\text { five biometric traits, flowering time, } \\
\text { electrolyte leakage, anthocyanin and } \\
\text { chlorophyll contents }\end{array}$ & {$[84]$} \\
\hline 10 & Cold $\left(4^{\circ} \mathrm{C}\right)$, heat $\left(38^{\circ} \mathrm{C}\right)$ & Gene expression & {$[88]$} \\
\hline 150 & $16^{\circ} \mathrm{C}$ & $\begin{array}{l}\text { Flowering time (day of flowering, total } \\
\text { leaf number at flowering) }\end{array}$ & {$[90]$} \\
\hline 52 & $25^{\circ} \mathrm{C}$ & $\begin{array}{l}\text { Flowering time (total leaf number at } \\
\text { flowering) }\end{array}$ & {$[65]$} \\
\hline \multirow[t]{2}{*}{23} & $10^{\circ} \mathrm{C}$ chronic exposure & $\begin{array}{l}\text { Root elongation rate, candidate genes } \\
\text { expression }\end{array}$ & {$[89]$} \\
\hline & \multicolumn{3}{|l|}{ Nutrient } \\
\hline 36 & $0,2,4$ or $6 \mathrm{~N}: \mathrm{P}: \mathrm{K}$ fertilizer doses & Biometric and fitness parameters & {$[29,109,110]$} \\
\hline $\begin{array}{l}36, \text { then } \\
5 \text { contrasted }\end{array}$ & 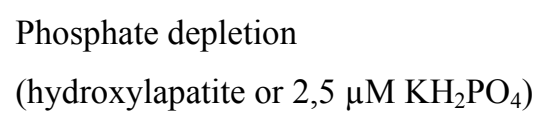 & $\begin{array}{l}\text { Root morphology parameters, phosphate } \\
\text { uptake kinetics }\end{array}$ & {$[107]$} \\
\hline 6 & $\begin{array}{l}\text { Phosphate depletion }(5 \mu \mathrm{M} \\
\left.\mathrm{NaH}_{2} \mathrm{PO}_{4}\right)\end{array}$ & Root morphology parameters & {$[108]$} \\
\hline & $\mathrm{CO}_{2}$ & & \\
\hline 3 & $\mathrm{CO}_{2}$ "enrichment" (550 ppm) & Gene expression, metabolite profile & {$[149]$} \\
\hline 35 & $\begin{array}{l}\mathrm{CO}_{2} \text { low, standard and enriched }(250 \\
\text { to } 710 \mathrm{ppm})\end{array}$ & $\begin{array}{l}\text { Biometric, developmental and metabolic } \\
\text { parameters }\end{array}$ & {$[151]$} \\
\hline 24 & $\begin{array}{l}\text { Reduce } \mathrm{CO}_{2} \text { assimilation (Short } \\
\text { days, low light, excess nitrate) }\end{array}$ & $\begin{array}{l}\text { Rosette weight, enzymes and metabolites } \\
\text { profile }\end{array}$ & {$[152]$} \\
\hline
\end{tabular}


Table 1. Cont.

\begin{tabular}{|c|c|c|c|}
\hline Accessions $^{1}$ & Stress & Trait & Reference \\
\hline & Root anoxie & & \\
\hline \multirow[t]{2}{*}{47} & $\begin{array}{l}\text { Soil saturated with water } \\
\text { (waterlogging) }\end{array}$ & Biometric parameters & {$[153]$} \\
\hline & Heavy metal & & \\
\hline \multirow[t]{2}{*}{260} & $\mathrm{Al}^{3+} 1 \mathrm{mM}$ or $\mathrm{pH} 4.7$ & Relative root length & {$[137]$} \\
\hline & Oxydative & & \\
\hline \multirow[t]{2}{*}{11} & Atrazine $(0.25,0.5 \mu \mathrm{M})$ & $\begin{array}{l}\text { Metabolic and root morphology } \\
\text { parameters, ROS accumulation }\end{array}$ & Ramel et al., in prep. \\
\hline & Osmotic (including drought, salt) & & \\
\hline 4 & $\begin{array}{l}5,10,15 \text { or } 20 \mathrm{~mL} \text { of water in } 2 \\
\text { inches pot }\end{array}$ & Biometric and fitness parameters & {$[29]$} \\
\hline 39 & No stress & WUE (delta $\left.{ }^{13} \mathrm{C}\right)$ & {$[31]$} \\
\hline 9 & Monitored drought stress & Projected leaves area, Transpiration rate & {$[33]$} \\
\hline 24 & Monitored mild drought stress & $\begin{array}{l}\text { Total Leaf Area, Relative Water Content, } \\
\text { Electrolyte Leackage, Cut Rosette Water } \\
\text { Loss }\end{array}$ & {$[34]$} \\
\hline 102 & $250 \mathrm{mM} \mathrm{NaCl}$ in vitro & Germination, Fresh weight, dry weight & {$[44]$} \\
\hline 12 & $100 \mathrm{mM} \mathrm{NaCl}$ in pots & Survival & {$[46]$} \\
\hline
\end{tabular}

\footnotetext{
${ }^{1}$ Only the studies that comprise more than two accessions are reported in this table.
} 
Table 2. Summary of the characteristics of the QTLs cloned, for abiotic environment-responsive traits in Arabidopsis.

\begin{tabular}{|c|c|c|c|c|c|c|c|c|c|c|c|c|}
\hline Trait & QTL & Gene & Function & Approach & ${ }^{\mathrm{a}} \mathbf{R}^{2} \%$ & $\begin{array}{c}{ }^{\text {b}} \text { Plant } \\
\text { number }\end{array}$ & $\begin{array}{c}{ }^{\mathrm{c}} \text { Resolution } \\
\text { (kb) }\end{array}$ & $\begin{array}{c}{ }^{\mathrm{d}} \text { Candidate } \\
\text { gene and } \\
\text { early or late } \\
\text { evidence } \\
\end{array}$ & $\begin{array}{l}\text { Identification } \\
\text { of QTN }\end{array}$ & Population & Functional proof & Reference \\
\hline $\begin{array}{l}\text { Photoperiod } \\
\text { responsive } \\
\text { flowering time }\end{array}$ & $E D 1$ & CRY2 & Cryptochrome & $\begin{array}{l}\text { Positional } \\
\text { cloning }\end{array}$ & $28-56$ & 1822 & 45 & Yes (late) & $\begin{array}{l}\text { Amino acid } \\
\text { substitution }\end{array}$ & Ler $\times$ Cvi & $\begin{array}{c}\text { Transgenic } \\
\text { complementation }\end{array}$ & {$[67]$} \\
\hline $\begin{array}{l}\text { Light } \\
\text { responsive } \\
\text { flowering time } \\
\text { and hypocotyls } \\
\text { elongation }\end{array}$ & - & PHYC & Phytochrome & $\begin{array}{l}\text { Positional } \\
\text { cloning }\end{array}$ & - & 140 & 1000 & Yes (early) & $\begin{array}{l}\text { Amino acid } \\
\text { substitution }\end{array}$ & Fr $-2 \times$ Col- 0 & $\begin{array}{c}\text { Quantative } \\
\text { complementation }\end{array}$ & {$[65]$} \\
\hline $\begin{array}{l}\text { Light } \\
\text { responsive } \\
\text { hypocotyls } \\
\text { elongation }\end{array}$ & LIGHT2 & РНYВ & Phytochrome & $\begin{array}{c}\text { Association } \\
\text { mapping }\end{array}$ & $18-22$ & $\begin{array}{c}140 \\
\text { accessio } \\
\text { ns }\end{array}$ & NA & Yes (early) & $\begin{array}{l}\text { Amino acid } \\
\text { substitution }\end{array}$ & Ler $\times$ Cvi & Transformation & {$[57]$} \\
\hline $\begin{array}{c}\text { Light } \\
\text { responsive } \\
\text { hypocotyls } \\
\text { elongation }\end{array}$ & LIGHT5 & $T Z P$ & Zinc Knucke & $\begin{array}{l}\text { Positional } \\
\text { cloning }\end{array}$ & 40 & 4600 & 7 & Yes (late) & $\begin{array}{l}\text { Premature } \\
\text { stop codon }\end{array}$ & Bay $-0 \times$ Sha & $\begin{array}{c}\text { Transgenic } \\
\text { complementation }\end{array}$ & {$[66]$} \\
\hline Sulfate content & SOC.1 & APR2 & $\begin{array}{c}5 '- \\
\text { Phosphosulfate } \\
\text { reductase }\end{array}$ & $\begin{array}{l}\text { Positional } \\
\text { cloning }\end{array}$ & 48 & 411 & 4000 & Yes (early) & $\begin{array}{l}\text { Amino acid } \\
\text { substitution }\end{array}$ & Bay $-0 \times$ Sha & $\begin{array}{l}\text { Transgenic and } \\
\text { quantitative } \\
\text { complementation }\end{array}$ & [116] \\
\hline $\begin{array}{l}\text { Molybdate } \\
\text { content }\end{array}$ & - & MOT1 & Mo transporter & $\begin{array}{l}\text { Positional } \\
\text { cloning }\end{array}$ & - & 18 & 172 & Yes (early) & $\begin{array}{l}\text { 53-bp } \\
\text { deletion in } \\
\text { promoter }\end{array}$ & Ler $\times$ Col- 0 & $\begin{array}{l}\text { Heterologous } \\
\text { system (yeast) }\end{array}$ & {$[125]$} \\
\hline $\begin{array}{c}\text { Molybdate } \\
\text { content }\end{array}$ & - & MOT1 & Mo transporter & $\begin{array}{l}\text { BSA- } \\
\text { Positional } \\
\text { cloning }\end{array}$ & - & 200 & 346 & Yes (early) & $\begin{array}{l}\text { 53-bp } \\
\text { deletion in } \\
\text { promoter }\end{array}$ & Ler $\times$ Col- 0 & $\begin{array}{c}\text { Quantitative } \\
\text { complementation }\end{array}$ & [124] \\
\hline $\begin{array}{c}\mathrm{Na}^{+} \\
\text {accumulation }\end{array}$ & - & $\begin{array}{l}\text { AtHK } \\
\text { T1 }\end{array}$ & $\begin{array}{c}\mathrm{Na}^{+} \\
\text {transporter }\end{array}$ & $\begin{array}{l}\text { BSA- } \\
\text { Positional } \\
\text { cloning }\end{array}$ & - & 60 & 2000 & Yes (early) & $\begin{array}{l}\text { Deletion in } \\
\text { upstream of } \\
\text { AtHKT1 }\end{array}$ & $\begin{array}{c}\text { Ts- } 1 \text {, Tsu- } 1 \times \\
\text { Col-0 }\end{array}$ & $\begin{array}{c}\text { Quantitative } \\
\text { complementation }\end{array}$ & {$[46]$} \\
\hline
\end{tabular}

${ }^{\mathrm{a}}$ Percentage of phenotypic variance explained by QTL; ${ }^{\mathrm{b}}$ Number of plant screened; ${ }^{\mathrm{c}}$ Map resolution; ${ }^{\mathrm{d}}$ Along the fine mapping process. 


\section{Acknowledgements}

We are grateful to Olivier Loudet, Georges Pelletier and Marie-Noëlle Fortabat for their critical reading of this manuscript and for their availability to discuss any scientific or technique matter.

\section{References and Notes}

1. The Arabidopsis Initiative. Analysis of the genome sequence of the flowering plant Arabidopsis thaliana. Nature 2000, 408, 796-815.

2. Borevitz, J.O.; Hazen, S.P.; Michael, T.P.; Morris, G.P.; Baxter, I.R.; Hu, T.T.; Chen, H.; Werner, J.D.; Nordborg, M.; Salt, D.E.; Kay, S.A.; Chory, J.; Weigel, D.; Jones, J.D.; Ecker, J.R. Genome-wide patterns of single-feature polymorphism in Arabidopsis thaliana. Proc. Nat. Acad. Sci. USA 2007, 104, 12057-12062.

3. Clark, R.M.; Schweikert, G.; Toomajian, C.; Ossowski, S.; Zeller, G.; Shinn, P.; Warthmann, N.; Hu, T.T.; Fu, G.; Hinds, D.A.; Chen, H.; Frazer, K.A.; Huson, D.H.; Scholkopf, B.; Nordborg, M.; Ratsch, G.; Ecker, J.R.; Weigel, D. Common sequence polymorphisms shaping genetic diversity in Arabidopsis thaliana. Science 2007, 317, 338-342.

4. Koornneef, M.; Alonso-Blanco, C.; Vreugdenhil, D. Naturally occurring genetic variation in Arabidopsis thaliana. Annu. Rev. Plant Biol. 2004, 55, 141-172.

5. Nordborg, M.; Hu, T.T.; Ishino, Y.; Jhaveri, J.; Toomajian, C.; Zheng, H.; Bakker, E.; Calabrese, P.; Gladstone, J.; Goyal, R.; Jakobsson, M.; Kim, S.; Morozov, Y.; Padhukasahasram, B.; Plagnol, V.; Rosenberg, N.A.; Shah, C.; Wall, J.D.; Wang, J.; Zhao, K.; Kalbfleisch, T.; Schulz, V.; Kreitman, M.; Bergelson, J. The pattern of polymorphism in Arabidopsis thaliana. PLoS Biol. 2005, 3, e196.

6. Ostrowski, M.F.; David, J.; Santoni, S.; McKhann, H.; Reboud, X.; Le Corre, V.; Camilleri, C.; Brunel, D.; Bouchez, D.; Faure, B.; Bataillon, T. Evidence for a large-scale population structure among accessions of Arabidopsis thaliana: Possible causes and consequences for the distribution of linkage disequilibrium. Mol. Ecol. 2006, 15, 1507-1517.

7. Pico, F.X.; Mendez-Vigo, B.; Martinez-Zapater, J.M.; Alonso-Blanco, C. Natural genetic variation of Arabidopsis thaliana is geographically structured in the Iberian Peninsula. Genetics 2008, 180, 1009-1021.

8. Schmid, K.J.; Ramos-Onsins, S.; Ringys-Beckstein, H.; Weisshaar, B.; Mitchell-Olds, T. A multilocus sequence survey in Arabidopsis thaliana reveals a genome-wide departure from a neutral model of DNA sequence polymorphism. Genetics 2005, 169, 1601-1615.

9. Schmid, K.J.; Torjek, O.; Meyer, R.; Schmuths, H.; Hoffmann, M.H.; Altmann, T. Evidence for a large-scale population structure of Arabidopsis thaliana from genome-wide single nucleotide polymorphism markers. Theor. Appl. Genet. 2006, 112, 1104-1114.

10. Beck, J.B.; Schmuths, H.; Schaal, B.A. Native range genetic variation in Arabidopsis thaliana is strongly geographically structured and reflects Pleistocene glacial dynamics. Mol. Ecol. 2008, 17, 902-915.

11. Boyer, J.S. Plant productivity and environment. Science 1982, 218, 443-448. 
12. Xiong, L.; Zhu, J.-K. Abiotic stress signal transduction in plants: Molecular and genetic perspectives. Physiol. Plant. 2001, 112, 152-166.

13. Viswanathan, C.; Zhu, J.K. Molecular genetic analysis of cold-regulated gene transcription. Philos. Trans. R. Soc. Lond. B Biol. Sci. 2002, 357, 877-886.

14. Laloi, C.; Przybyla, D.; Apel, K. A genetic approach towards elucidating the biological activity of different reactive oxygen species in Arabidopsis thaliana. J. Exp. Bot. 2006, 57, 1719-1724.

15. Grene, R. Oxidative stress and acclimation mechanisms in plants. In The Arabidopsis Book; American Society of Plant Biologists: Rockville, MD, USA, 2002.

16. Bonhert, H.J.; Sheveleva, E. Plant stress adaptations-Making metabolism move. Curr. Opin. Plant Biol. 1998, 1, 267-274.

17. McAinsh, M.R.; Brownlee, C.; Hetherington, A.M. Calcium ions as second messengers in guard cell signal transduction. Physiol. Plant. 1997, 100, 16-29.

18. Xiong, L.; Zhu, J.-K. Salt tolerance. In The Arabidopsis Book; American Society of Plant Biologists: Rockville, MD, USA, 2002.

19. Mittler, R. Abiotic stress, the field environment and stress combination. Trends Plant Sci. 2006, 11, 15-19.

20. van Volkenburgh, E. Leaf expension-An integrating plant behaviour. Plant Cell Environ. 1999, 22, 1463-1473.

21. Gilmour, S.J.; Hajela, R.K.; Thomashow, M.F. Cold acclimation in Arabidopsis thaliana. Plant Physiol. 1988, 87, 745-750.

22. Mackay, T.F. The genetic architecture of quantitative traits. Annu. Rev. Genet. 2001, 35, 303339.

23. Peters, J.L.; Cnudde, F.; Gerats, T. Forward genetics and map-based cloning approaches. Trends Plant Sci. 2003, 8, 484-491.

24. Borevitz, J.O.; Chory, J. Genomics tools for QTL analysis and gene discovery. Curr. Opin. Plant Biol. 2004, 7, 132-136.

25. Borevitz, J.O.; Nordborg, M. The impact of genomics on the study of natural variation in Arabidopsis. Plant Physiol. 2003, 132, 718-725.

26. Chaves, M.M.; Maroco, J.P.; Pereira, J.S. Understanding plant responses to drought-From genes to the whole plant. Funct. Plant Biol. 2003, 30, 239-264.

27. Ludlow, M. Strategies of response to water stress. In Structural and Functional Responses to Environmental Stresses. SPB Academic.: The Hague, The Netherlands., 1989; pp. 269-281.

28. Tambussi, E.A.; Bort, J.; Araus, J.L. Wate use efficiency in C3 cereals under mediterranean conditions: A review of physiological aspects. Ann. Appl. Biol. 2007, 150, 307-321.

29. Pigliucci, M.; Whitton, J.; Schlichting, C.D. Reaction norms of Arabidopsis. I. Plasticity of characters and correlations across water, nutrient and light gradients. J. Evol. Biol. 1995, 8, 421-438.

30. Meyre, D.; Leonardi, A.; Brisson, G.; Vartanian, N. Drought-adaptive mechanisms involved in the escape/tolerance strategies of Arabidopsis Landsberg erecta and Columbia ecotypes and their F1 reciprocal progeny. J. Plant Physiol. 2001, 158, 1145-1152. 
31. McKay, J.K.; Richards, J.H.; Mitchell-Olds, T. Genetics of drought adaptation in Arabidopsis thaliana: I. Pleiotropy contributes to genetic correlations among ecological traits. Mol. Ecol. 2003, 12, 1137-1151.

32. Farquhar, G.D.; O'Leary, M.H.; Berry, J.A. On the relationship between carbon isotop discrimination and the intercellular carbon dioxide concentration in leaves. Aust. J. Plant Physiol. 1982, 9, 121-137.

33. Granier, C.; Aguirrezabal, L.; Chenu, K.; Cookson, S.J.; Dauzat, M.; Hamard, P.; Thioux, J.J.; Rolland, G.; Bouchier-Combaud, S.; Lebaudy, A.; Muller, B.; Simonneau, T.; Tardieu, F. PHENOPSIS, an automated platform for reproducible phenotyping of plant responses to soil water deficit in Arabidopsis thaliana permitted the identification of an accession with low sensitivity to soil water deficit. New Phytol. 2006, 169, 623-635.

34. Bouchabke, O.; Chang, F.; Simon, M.; Voisin, R.; Pelletier, G.; Durand-Tardif, M. Natural variation in Arabidopsis thaliana as a tool for highlighting differential drought responses. PLoS ONE 2008, 3, e1705.

35. Hausmann, N.J.; Juenger, T.E.; Sen, S.; Stowe, K.A.; Dawson, T.E.; Simms, E.L. Quantitative trait loci affecting delta $\mathrm{C}-13$ and response to differential water availibility in Arabidopsis thaliana. Evolution 2005, 59, 81-96.

36. Ungerer, M.C.; Halldorsdottir, S.S.; Purugganan, M.A.; Mackay, T.F.C. Genotype-environment interactions at quantitative trait loci affecting inflorescence development in Arabidopsis thaliana. Genetics 2003, 165, 353-365.

37. Juenger, T.E.; McKay, J.K.; Hausmann, N.; Keurentjes, J.J.B.; Sen, S.; Stowe, K.A.; Dawson, T.E.; Simms, E.L.; Richards, J.H. Identification and characterization of QTL underlying wholeplant physiology in Arabidopsis thaliana: Delta C-13, stomatal conductance and transpiration efficiency. Plant Cell Environ. 2005, 28, 697-708.

38. McKay, J.K.; Richards, J.H.; Nemali, K.S.; Sen, S.; Mitchell-Olds, T.; Boles, S.; Stahl, E.A.; Wayne, T.; Juenger, T.E. Genetics of drought adaptation in Arabidopsis thaliana II. QTL analysis of a new mapping population, Kas-1 $\times$ Tsu-1. Evolution 2008, 62, 3014-3026.

39. Masle, J.; Gilmore, S.R.; Farquhar, G.D. The ERECTA gene regulates plant transpiration efficiency in Arabidopsis. Nature 2005, 436, 866-870.

40. Deak, K.I.; Malamy, J. Osmotic regulation of root system architecture. Plant J. 2005, 43, 17-28.

41. Fitz Gerald, J.N.; Lehti-Shiu, M.D.; Ingram, P.A.; Deak, K.I.; Biesiada, T.; Malamy, J.E. Identification of quantitative trait loci that regulate Arabidopsis root system size and plasticity. Genetics 2006, 172, 485-498.

42. Munns, R. Genes and salt tolerance: Bringing them together. New Phytol. 2005, 167, 645-663.

43. Amzallag, G.N.; Lerner, H.R.; Poljakoff-Mayber, A. Induction of increased salt tolerance in sorghum bicolor by $\mathrm{NaCl}$ pretreatment. J. Exp. Bot. 1990, 41, 29-34.

44. Quesada, V.; Garcia-Martinez, S.; Piqueras, P.; Ponce, M.R.; Micol, J.L. Genetic architecture of $\mathrm{NaCl}$ tolerance in Arabidopsis. Plant Physiol. 2002, 130, 951-963.

45. Liu, J.; Ishitani, M.; Halfter, U.; Kim, C.S.; Zhu, J.K. The Arabidopsis thaliana SOS2 gene encodes a protein kinase that is required for salt tolerance. Proc. Nat. Acad. Sci. USA 2000, 97, 3730-3734. 
46. Rus, A.; Baxter, I.; Muthukumar, B.; Gustin, J.; Lahner, B.; Yakubova, E.; Salt, D.E. Natural variants of AtHKT1 enhance $\mathrm{Na}(+)$ accumulation in two wild populations of Arabidopsis. PLoS Genet. 2006, 2, e210.

47. Berthomieu, P.; Conejero, G.; Nublat, A.; Brackenbury, W.J.; Lambert, C.; Savio, C.; Uozumi, N.; Oiki, S.; Yamada, K.; Cellier, F.; Gosti, F.; Simonneau, T.; Essah, P.A.; Tester, M.; Very, A.A.; Sentenac, H.; Casse, F. Functional analysis of AtHKT1 in Arabidopsis shows that $\mathrm{Na}(+)$ recirculation by the phloem is crucial for salt tolerance. Embo. J. 2003, 22, 2004-2014.

48. Gong, J.M.; Waner, D.A.; Horie, T.; Li, S.L.; Horie, R.; Abid, K.B.; Schroeder, J.I. Microarraybased rapid cloning of an ion accumulation deletion mutant in Arabidopsis thaliana. Proc. Nat. Acad. Sci. USA 2004, 101, 15404-15409.

49. Uozumi, N.; Kim, E.J.; Rubio, F.; Yamaguchi, T.; Muto, S.; Tsuboi, A.; Bakker, E.P.; Nakamura, T.; Schroeder, J.I. The Arabidopsis HKT1 gene homolog mediates inward $\mathrm{Na}(+)$ currents in xenopus laevis oocytes and $\mathrm{Na}(+)$ uptake in Saccharomyces cerevisiae. Plant Physiol. 2000, 122, 1249-1259.

50. Rus, A.; Lee, B.H.; Munoz-Mayor, A.; Sharkhuu, A.; Miura, K.; Zhu, J.K.; Bressan, R.A.; Hasegawa, P.M. AtHKT1 facilitates $\mathrm{Na}+$ homeostasis and $\mathrm{K}+$ nutrition in planta. Plant Physiol. 2004, 136, 2500-2511.

51. Essah, P.A.; Davenport, R.; Tester, M. Sodium influx and accumulation in Arabidopsis. Plant Physiol. 2003, 133, 307-318.

52. Komeda, Y. Genetic regulation of time to flower in Arabidopsis thaliana. Annu. Rev. Plant Biol. 2004, 55, 521-535.

53. Roux, F.; Touzet, P.; Cuguen, J.; Le Corre, V. How to be early flowering: An evolutionary perspective. Trends Plant Sci. 2006, 11, 375-381.

54. Schepens, I.; Duek, P.; Fankhauser, C. Phytochrome-mediated light signalling in Arabidopsis. Curr. Opin. Plant Biol. 2004, 7, 564-569.

55. Botto, J.F.; Smith, H. Differential genetic variation in adaptive strategies to a common environmental signal in Arabidopsis accessions: Phytochrome-mediated shade avoidance. Plant Cell Environ. 2002, 25, 53-63.

56. Poulson, M.E.; Boeger, M.R.; Donahue, R.A. Response of photosynthesis to high light and drought for Arabidopsis thaliana grown under a UV-B enhanced light regime. Photosynth. Res. 2006, 90, 79-90.

57. Filiault, D.L.; Wessinger, C.A.; Dinneny, J.R.; Lutes, J.; Borevitz, J.O.; Weigel, D.; Chory, J.; Maloof, J.N. Amino acid polymorphisms in Arabidopsis phytochrome B cause differential responses to light. Proc. Nat. Acad. Sci. USA 2008, 105, 3157-3162.

58. Abarca, D.; Roldan, M.; Martin, M.; Sabater, B. Arabidopsis thaliana ecotype Cvi shows an increased tolerance to photo-oxidative stress and contains a new chloroplastic copper/zinc superoxide dismutase isoenzyme. J. Exp. Bot. 2001, 52, 1417-1425.

59. Maloof, J.N.; Borevitz, J.O.; Dabi, T.; Lutes, J.; Nehring, R.B.; Redfern, J.L.; Trainer, G.T.; Wilson, J.M.; Asami, T.; Berry, C.C.; Weigel, D.; Chory, J. Natural variation in light sensitivity of Arabidopsis. Nat. Genet. 2001, 29, 441-446.

60. Bae, G.; Choi, G. Decoding of light signals by plant phytochromes and their interacting proteins. Annu. Rev. Plant Biol. 2008, 59, 281-311. 
61. Botto, J.F.; Alonso-Blanco, C.; Garzaron, I.; Sanchez, R.A.; Casal, J.J. The Cape Verde Islands allele of cryptochrome 2 enhances cotyledon unfolding in the absence of blue light in Arabidopsis. Plant Physiol. 2003, 133, 1547-1556.

62. Magliano, T.M.; Botto, J.F.; Godoy, A.V.; Symonds, V.V.; Lloyd, A.M.; Casal, J.J. New Arabidopsis recombinant inbred lines (Landsberg erecta $\times$ Nossen) reveal natural variation in phytochrome-mediated responses. Plant Physiol. 2005, 138, 1126-1135.

63. Torabinejad, J.; Caldwell, M.M. Inheritance of UV-B tolerance in seven ecotypes of Arabidopsis thaliana L. Heynh. and their F1 hybrids. J. Hered. 2000, 91, 228-233.

64. Cooley, N.M.; Higgins, J.T.; Holmes, M.G.; Attridge, T.H. Ecotypic differences in responses of Arabidopsis thaliana L. to elevated polychromatic UV-A and UV-B + A radiation in the natural environment: A positive correlation between UV-B $+\mathrm{A}$ inhibition and growth rate. $J$. Photochem. Photobiol. B 2001, 60, 143-150.

65. Balasubramanian, S.; Sureshkumar, S.; Lempe, J.; Weigel, D. Potent induction of Arabidopsis thaliana flowering by elevated growth temperature. PLoS Genet. 2006, 2, e106.

66. Loudet, O.; Michael, T.P.; Burger, B.T.; Le Mette, C.; Mockler, T.C.; Weigel, D.; Chory, J. A zinc knuckle protein that negatively controls morning-specific growth in Arabidopsis thaliana. Proc. Nat. Acad. Sci. USA 2008, 105, 17193-17198.

67. El-Assal, S.E.D.; Alonso-Blanco, C.; Peeters, A.J.; Raz, V.; Koornneef, M. A QTL for flowering time in Arabidopsis reveals a novel allele of CRY2. Nat. Genet. 2001, 29, 435-440.

68. Olsen, K.M.; Halldorsdottir, S.S.; Stinchcombe, J.R.; Weinig, C.; Schmitt, J.; Purugganan, M.D. Linkage disequilibrium mapping of Arabidopsis CRY2 flowering time alleles. Genetics 2004, 167, 1361-1369.

69. Werner, J.D.; Borevitz, J.O.; Warthmann, N.; Trainer, G.T.; Ecker, J.R.; Chory, J.; Weigel, D. Quantitative trait locus mapping and DNA array hybridization identify an FLM deletion as a cause for natural flowering-time variation. Proc. Nat. Acad. Sci. USA 2005, 102, 2460-2465.

70. Guo, H.; Yang, H.; Mockler, T.C.; Lin, C. Regulation of flowering time by Arabidopsis photoreceptors. Science 1998, 279, 1360-1363.

71. Wolyn, D.J.; Borevitz, W.O.; Loudet, O.; Schwartz, C.; Maloof, J.; Ecker, J.R.; Berry, C.C.; Chory, J. Light-response quantitative trait loci identified with composite interval and eXtreme array mapping in Arabidopsis thaliana. Genetics 2004, 167, 907-917.

72. Franklin, K.A. Shade avoidance. New Phytol. 2008, 179, 930-944.

73. Chory, J.; Li, J. Gibberellins, brassinosteroids and light-regulated development. Plant Cell Environ. 1997, 20, 801-806.

74. Borevitz, J.O.; Maloof, J.N.; Lutes, J.; Dabi, T.; Redfern, J.L.; Trainer, G.T.; Werner, J.D.; Asami, T.; Berry, C.C.; Weigel, D.; Chory, J. Quantitative trait loci controlling light and hormone response in two accessions of Arabidopsis thaliana. Genetics 2002, 160, 683-696.

75. Thomashow, M.F. Plant cold acclimation: Freezing tolerance genes and regulatory mechanisms. Annu. Rev. Plant Physiol. Plant Mol. Biol. 1999, 50, 571-599.

76. Levitt, J. Chilling, freezing and high temperature stress. In Responses of Plants to Environmental Stresses; Academic: New York, USA, 1980; pp. 3-56. 
77. Lugan, R.; Niogret, M.F.; Kervazo, L.; Larher, F.R.; Kopka, J.; Bouchereau, A. Metabolome and water status phenotyping of Arabidopsis under abiotic stress cues reveals new insight into ESK1 function. Plant Cell Environ. 2009, 32, 95-108.

78. Xin, Z.; Browse, J. Eskimo1 mutants of Arabidopsis are constitutively freezing-tolerant. Proc. Nat. Acad. Sci. USA 1998, 95, 7799-7804.

79. Bouchabke-Coussa, O.; Quashie, M.L.; Seoane-Redondo, J.; Fortabat, M.N.; Gery, C.; Yu, A.; Linderme, D.; Trouverie, J.; Granier, F.; Teoule, E.; Durand-Tardif, M. ESKIMO1 is a key gene involved in water economy as well as cold acclimation and salt tolerance. BMC Plant Biol. 2008, 8, 125.

80. Smallwood, M.; Bowles, D.J. Plants in a cold climate. Philos. Trans. R. Soc. Lond. B Biol. Sci. 2002, 357, 831-847.

81. Le, M.Q.; Engelsberger, W.R.; Hincha, D.K. Natural genetic variation in acclimation capacity at sub-zero temperatures after cold acclimation at 4 degrees $\mathrm{C}$ in different Arabidopsis thaliana accessions. Cryobiology 2008, 57, 104-112.

82. Soitamo, A.J.; Piippo, M.; Allahverdiyeva, Y.; Battchikova, N.; Aro, E.M. Light has a specific role in modulating Arabidopsis gene expression at low temperature. BMC Plant Biol. 2008, 8, 13.

83. Rohde, P.; Hincha, D.K.; Heyer, A.G. Heterosis in the freezing tolerance of crosses between two Arabidopsis thaliana accessions (Columbia-0 and C24) that show differences in non-acclimated and acclimated freezing tolerance. Plant J. 2004, 38, 790-799.

84. Hasdai, M.; Weiss, B.; Levi, A.; Samach, A.; Porat, R. Differential responses of Arabidopsis ecotypes to cold, chilling and freezing temperatures. Ann. Appl. Biol. 2006, 148, 113-120.

85. Zhen, Y.; Ungerer, M.C. Clinal variation in freezing tolerance among natural accessions of Arabidopsis thaliana. New Phytol. 2008, 177, 419-427.

86. McKhann, H.I.; Gery, C.; Berard, A.; Leveque, S.; Zuther, E.; Hincha, D.K.; de Mita, S.; Brunel, D.; Teoule, E. Natural variation in $\mathrm{CBF}$ gene sequence, gene expression and freezing tolerance in the Versailles core collection of Arabidopsis thaliana. BMC Plant Biol. 2008, 8, 105.

87. Hannah, M.A.; Wiese, D.; Freund, S.; Fiehn, O.; Heyer, A.G.; Hincha, D.K. Natural genetic variation of freezing tolerance in Arabidopsis. Plant Physiol. 2006, 142, 98-112.

88. Swindell, W.R.; Huebner, M.; Weber, A.P. Plastic and adaptive gene expression patterns associated with temperature stress in Arabidopsis thaliana. Heredity 2007, 99, 143-150.

89. Lee, Y.P.; Fleming, A.J.; Korner, C.; Meins, F., Jr. Differential expression of the CBF pathway and cell cycle-related genes in Arabidopsis accessions in response to chronic low-temperature exposure. Plant Biol. (Stuttg) 2009, 11, 273-283.

90. Lempe, J.; Balasubramanian, S.; Sureshkumar, S.; Singh, A.; Schmid, M.; Weigel, D. Diversity of flowering responses in wild Arabidopsis thaliana strains. PLoS Genet. 2005, 1, 109-118.

91. Stinchcombe, J.R.; Dorn, L.A.; Schmitt, J. Flowering time plasticity in Arabidopsis thaliana: A reanalysis of Westerman \& Lawrence (1970). J. Evol. Biol. 2004, 17, 197-207.

92. Alonso-Blanco, C.; Gomez-Mena, C.; Llorente, F.; Koornneef, M.; Salinas, J.; Martinez-Zapater, J.M. Genetic and molecular analyses of natural variation indicate CBF2 as a candidate gene for underlying a freezing tolerance quantitative trait locus in Arabidopsis. Plant Physiol. 2005, 139, 1304-1312. 
93. Zarka, D.G.; Vogel, J.T.; Cook, D.; Thomashow, M.F. Cold induction of Arabidopsis CBF genes involves multiple ICE (inducer of CBF expression) promoter elements and a cold-regulatory circuit that is desensitized by low temperature. Plant Physiol. 2003, 133, 910-918.

94. Novillo, F.; Alonso, J.M.; Ecker, J.R.; Salinas, J. CBF2/DREB1C is a negative regulator of CBF1/DREB1B and CBF3/DREB1A expression and plays a central role in stress tolerance in Arabidopsis. Proc. Nat. Acad. Sci. USA 2004, 101, 3985-3990.

95. Lahner, B.; Gong, J.; Mahmoudian, M.; Smith, E.L.; Abid, K.B.; Rogers, E.E.; Guerinot, M.L.; Harper, J.F.; Ward, J.M.; McIntyre, L.; Schroeder, J.I.; Salt, D.E. Genomic scale profiling of nutrient and trace elements in Arabidopsis thaliana. Nat. Biotechnol. 2003, 21, 1215-1221.

96. Salt, D.E. Update on plant ionomics. Plant Physiol. 2004, 136, 2451-2456.

97. Nord, E.A.; Lynch, J.P. Delayed reproduction in Arabidopsis thaliana improves fitness in soil with suboptimal phosphorus availability. Plant Cell Environ. 2008, 31, 1432-1441.

98. Jovanovic, M.; Lefebvre, V.; Laporte, P.; Gonzalez-Rizzo, S.; Lelandais-Briére, C.; Frugier, F.; Hartmann, C.; Crespi, M. How the environment regulates root architecture in dicots. Adv. Botanical Res. 2007, 46, 35-74.

99. Raghothama, K.G. Phosphate acquisition. Annu. Rev. Plant Physiol. 1999, 50, 665-693.

100. Lopez-Bucio, J.; Cruz-Ramirez, A.; Herrera-Estrella, L. The role of nutrient availability in regulating root architecture. Curr. Opin. Plant Biol. 2003, 6, 280-287.

101. Torrey, J.G. Root hormones and plant growth. Annu. Rev. Plant Physiol. 1976, 27, 435-459.

102. Lopez-Bucio, J.; Hernandez-Abreu, E.; Sanchez-Calderon, L.; Nieto-Jacobo, M.F.; Simpson, J.; Herrera-Estrella, L. Phosphate availability alters architecture and causes changes in hormone sensitivity in the Arabidopsis root system. Plant Physiol. 2002, 129, 244-256.

103. Holford, I.C.R. Soil phosphorus: Its measurements and its uptake by plants. Aust. J. Soil Res. 1997, 35, 227-239.

104. Lopez-Bucio, J.; Nieto-Jacobo, M.F.; Ramirez-Rodriguez, V.V.; Herrera-Estrella, L. Organic acid metabolism in plants: From adaptive physiology to transgenic varieties for cultivation in extreme soils. Plant Sci. 2000, 160, 1-13.

105. Masclaux-Daubresse, C.; Reisdorf-Cren, M.; Orsel, M. Leaf nitrogen remobilisation for plant development and grain filling. Plant Biol. (Stuttg) 2008, 10 (Suppl 1), 23-36.

106. Scheible, W.R.; Morcuende, R.; Czechowski, T.; Fritz, C.; Osuna, D.; Palacios-Rojas, N.; Schindelasch, D.; Thimm, O.; Udvardi, M.K.; Stitt, M. Genome-wide reprogramming of primary and secondary metabolism, protein synthesis, cellular growth processes, and the regulatory infrastructure of Arabidopsis in response to nitrogen. Plant Physiol. 2004, 136, 2483-2499.

107. Narang, R.A.; Bruene, A.; Altmann, T. Analysis of phosphate acquisition efficiency in different Arabidopsis accessions. Plant Physiol. 2000, 124, 1786-1799.

108. Reymond, M.; Svistoonoff, S.; Loudet, O.; Nussaume, L.; Desnos, T. Identification of QTL controlling root growth response to phosphate starvation in Arabidopsis thaliana. Plant Cell Environ. 2006, 29, 115-125.

109. Pigliucci, M.; Schlichting, C.D.; Whitton, J. Reaction norms of Arabidopsis. II. Response to stress and unordered environmental variation. Funct. Ecol. 1995, 9, 537-547.

110. Pigliucci, M.; Schlichting, C.D. Reaction norms of Arabidopsis (Brassicaceae). III. Response to nutrients in 26 populations from a worldwide collection. Amer. J. Bot. 1995, 82, 1117-1125. 
111. Fricke, W.; Flowers, T.J. Control of leaf cell elongation in barley. Generation rates of osmotic pressure and turgor, and growth-associated water potential gradients. Planta 1998, 206, 53-65.

112. Loudet, O.; Chaillou, S.; Krapp, A.; Daniel-Vedele, F. Quantitative trait loci analysis of water and anion contents in interaction with nitrogen availability in Arabidopsis thaliana. Genetics 2003, 163, 711-722.

113. Loudet, O.; Chaillou, S.; Merigout, P.; Talbotec, J.; Daniel-Vedele, F. Quantitative trait loci analysis of nitrogen use efficiency in Arabidopsis. Plant Physiol. 2003, 131, 345-358.

114. Svistoonoff, S.; Creff, A.; Reymond, M.; Sigoillot-Claude, C.; Ricaud, L.; Blanchet, A.; Nussaume, L.; Desnos, T. Root tip contact with low-phosphate media reprograms plant root architecture. Nat. Genet. 2007, 39, 792-796.

115. Sanchez-Calderon, L.; Lopez-Bucio, J.; Chacon-Lopez, A.; Cruz-Ramirez, A.; Nieto-Jacobo, F.; Dubrovsky, J.G.; Herrera-Estrella, L. Phosphate starvation induces a determinate developmental program in the roots of Arabidopsis thaliana. Plant Cell Physiol. 2005, 46, 174-184.

116. Loudet, O.; Saliba-Colombani, V.; Camilleri, C.; Calenge, F.; Gaudon, V.; Koprivova, A.; North, K.A.; Kopriva, S.; Daniel-Vedele, F. Natural variation for sulfate content in Arabidopsis thaliana is highly controlled by APR2. Nat. Genet. 2007, 39, 896-900.

117. Shorrocks, V.M. The occurnece and correction of boron deficiency. Plant Soil 1997, 193, 121-148.

118. Zeng, C.; Han, Y.; Shi, L.; Peng, L.; Wang, Y.; Xu, F.; Meng, J. Genetic analysis of the physiological responses to low boron stress in Arabidopsis thaliana. Plant Cell Environ. 2008, $31,112-122$.

119. Tejada-Jimenez, M.; Llamas, A.; Sanz-Luque, E.; Galvan, A.; Fernandez, E. A high-affinity molybdate transporter in eukaryotes. Proc. Nat. Acad. Sci. USA 2007, 104, 20126-20130.

120. Schwarz, G.; Mendel, R.R. Molybdenum cofactor biosynthesis and molybdenum enzymes. Annu. Rev. Plant Biol. 2006, 57, 623-647.

121. Jander, G.; Norris, S.R.; Rounsley, S.D.; Bush, D.F.; Levin, I.M.; Last, R.L. Arabidopsis mapbased cloning in the post-genome era. Plant Physiol. 2002, 129, 440-450.

122. Wood, S.; Sebastian, K.; Scherr, S. Soil resource condition. In Pilot Analysis of Global Ecosystems: Agroecosystems; International Food Policy Research Institute and the World Resources Institute: Washington, DC, USA, 2000; pp. 45-54.

123. Smith, K.S.; Balistrieri, L.S.; Smith, S.M.; Severson, R.C. Distribution and mobility of molybdenum in the terrestrial environment. In Molybdenum in Agriculture; Gupta, U., Ed.; Cambridge University Press: Cambridge, UK, 1997.

124. Baxter, I.; Muthukumar, B.; Park, H.C.; Buchner, P.; Lahner, B.; Danku, J.; Zhao, K.; Lee, J.; Hawkesford, M.J.; Guerinot, M.L.; Salt, D.E. Variation in molybdenum content across broadly distributed populations of Arabidopsis thaliana is controlled by a mitochondrial molybdenum transporter (MOT1). PLoS Genet. 2008, 4, e1000004.

125. Tomatsu, H.; Takano, J.; Takahashi, H.; Watanabe-Takahashi, A.; Shibagaki, N.; Fujiwara, T. An Arabidopsis thaliana high-affinity molybdate transporter required for efficient uptake of molybdate from soil. Proc. Nat. Acad. Sci. USA 2007, 104, 18807-18812.

126. Clemens, S. Toxic metal accumulation, responses to exposure and mechanisms of tolerance in plants. Biochimie 2006, 88, 1707-1719. 
127. Hoekenga, O.A.; Vision, T.J.; Shaff, J.E.; Monforte, A.J.; Lee, G.P.; Howell, S.H.; Kochian, L.V. Identification and characterization of aluminum tolerance loci in Arabidopsis (Landsberg erecta $\times$ Columbia) by quantitative trait locus mapping. A physiologically simple but genetically complex trait. Plant Physiol. 2003, 132, 936-948.

128. Kobayashi, Y.; Hoekenga, O.A.; Itoh, H.; Nakashima, M.; Saito, S.; Shaff, J.E.; Maron, L.G.; Pineros, M.A.; Kochian, L.V.; Koyama, H. Characterization of AtALMT1 expression in aluminum-inducible malate release and its role for rhizotoxic stress tolerance in Arabidopsis. Plant Physiol. 2007, 145, 843-852.

129. Schutzendubel, A.; Polle, A. Plant responses to abiotic stresses: Heavy metal-induced oxidative stress and protection by mycorrhization. J. Exp. Bot. 2002, 53, 1351-1365.

130. Courbot, M.; Willems, G.; Motte, P.; Arvidsson, S.; Roosens, N.; Saumitou-Laprade, P.; Verbruggen, N. A major QTL for Cd tolerance in Arabidopsis halleri Co-localizes with HMA4, a gene encoding a heavy metal ATPase. Plant Physiol. 2007, 144, 1052-1065.

131. Kochian, L.V. Cellular mechanisms of aluminum toxicity and resistance in plants. Annu. Rev. Plant Physiol. Plant Mol. Biol. 1995, 46, 237-260.

132. Taylor, G.J. Current views of aluminum stress response: The physiological basis of tolerance. Curr. Topics Plant Biochem. Physiol. 1991, 6, 57-93.

133. Ma, J.F.; Ryan, P.R.; Delhaize, E. Aluminium tolerance in plants and the complexing role of organic acids. Trends Plant Sci. 2001, 6, 273-278.

134. Yamamoto, Y.; Hachiya, A.; Matsumoto, H. Oxidative damage to membranes by a combination of aluminum and iron in suspension cultured tobacco cells. Plant Cell Physiol. 1997, 38, 1333-1339.

135. Degenhardt, J.; Larsen, P.B.; Howell, S.H.; Kochian, L.V. Aluminum resistance in the Arabidopsis mutant alr-104 is caused by an aluminum-induced increase in rhizosphere $\mathrm{pH}$. Plant Physiol. 1998, 117, 19-27.

136. Delhaize, E.; Hebb, D.M.; Ryan, P.R. Expression of a Pseudomonas aeruginosa citrate synthase gene in tobacco is not associated with either enhanced citrate accumulation or efflux. Plant Physiol. 2001, 125, 2059-2067.

137. Ikka, T.; Kobayashi, Y.; Iuchi, S.; Sakurai, N.; Shibata, D.; Kobayashi, M.; Koyama, H. Natural variation of Arabidopsis thaliana reveals that aluminum resistance and proton resistance are controlled by different genetic factors. Theor. Appl. Genet. 2007, 115, 709-719.

138. Kobayashi, Y.; Koyama, H. QTL analysis of Al tolerance in recombinant inbred lines of Arabidopsis thaliana. Plant Cell Physiol. 2002, 43, 1526-1533.

139. Takita, E.; Koyama, H.; Hara, T. Organic acid in aluminum-phosphate utilizing cell of carrot (Daucus carota L.). Plant Cell Physiol. 1999, 40, 489-495.

140. Larsen, P.B.; Degenhardt, J.; Tai, C.Y.; Stenzler, L.M.; Howell, S.H.; Kochian, L.V. Aluminumresistant Arabidopsis mutants that exhibit altered patterns of aluminum accumulation and organic acid release from roots. Plant Physiol. 1998, 117, 9-18.

141. Larsen, P.B.; Tai, C.Y.; Kochian, L.V.; Howell, S.H. Arabidopsis mutants with increased sensitivity to aluminum. Plant Physiol. 1996, 110, 743-751. 
142. Ezaki, B.; Gardner, R.C.; Ezaki, Y.; Matsumoto, H. Expression of aluminum-induced genes in transgenic Arabidopsis plants can ameliorate aluminum stress and/or oxidative stress. Plant Physiol. 2000, 122, 657-665.

143. Hoekenga, O.A.; Maron, L.G.; Pineros, M.A.; Cancado, G.M.; Shaff, J.; Kobayashi, Y.; Ryan, P.R.; Dong, B.; Delhaize, E.; Sasaki, T.; Matsumoto, H.; Yamamoto, Y.; Koyama, H.; Kochian, L.V. AtALMT1, which encodes a malate transporter, is identified as one of several genes critical for aluminum tolerance in Arabidopsis. Proc. Nat. Acad. Sci. USA 2006, 103, 9738-9743.

144. Prentice, I.C.; Farquhar, G.D.; Fasham, M.; Goulden, M.; Jaramillo, V.; Kheshgi, H.; Quere, C.; Scholes, R.; Wallace, D. The carbon cycle and atmospheric $\mathrm{CO}_{2}$. In Climate Change 2001: The Scientific Basis. Contribution of Working Group 1 to the Third Assessment Report of the Intergovernmental Panel on Climate Change; Houghton, J.T., Ding, Y., Griggs, D.J., Noguer, M., van der Linden, P.J., Dai, X., Maskell, K., Johnson, C.A., Eds.; Cambridge University Press: Cambridge, UK, 2001; pp. 183-237.

145. Ainsworth, E.A.; Rogers, A. The response of photosynthesis and stomatal conductance to rising $\left[\mathrm{CO}_{2}\right]$ : Mechanisms and environmental interactions. Plant Cell Environ. 2007, 30, 258-270.

146. Long, S.P.; Ainsworth, E.A.; Rogers, A.; Ort, D.R. Rising atmospheric carbon dioxide: Plants FACE the future. Annu. Rev. Plant Biol. 2004, 55, 591-628.

147. Li, P.; Ainsworth, E.A.; Leakey, A.D.; Ulanov, A.; Lozovaya, V.; Ort, D.R.; Bohnert, H.J. Arabidopsis transcript and metabolite profiles: Ecotype-specific responses to open-air elevated [CO $\mathrm{CO}_{2}$. Plant Cell Environ. 2008, 31, 1673-1687.

148. Zhang, J.; Lechowicz, M.J. Responses to $\mathrm{CO}_{2}$ enrichment by two genotypes of Arabidopsis thaliana differing in their sensitivity to nutrient availability. Ann. Bot. 1995, 75, 491-499.

149. Li, P.H.; Sioson, A.; Mane, S.P.; Ulanov, A.; Grothaus, G.; Heath, L.S.; Murali, T.M.; Bohnert, H.J.; Grene, R. Response diversity of Arabidopsis thaliana ecotypes in elevated $\mathrm{CO}_{2}$ in the field. Plant Mol. Biol. 2006, 62, 593-609.

150. Miyazaki, S.; Fredricksen, M.; Hollis, K.C.; Poroyko, V.; Shelpley, D.; Galbraith, D.W.; Long, S.P.; Bohnert, H.J. Transcript expression profiles of Arabidopsis thaliana grown under controlled conditions and open-air elevated concentrations of $\mathrm{CO}_{2}$ and of $\mathrm{O}_{3}$. Field Crops Res. 2004, 90, 47-59.

151. Tonsor, S.J.; Scheiner, S.M. Plastic trait integration across a $\mathrm{CO}_{2}$ gradient in Arabidopsis thaliana. Am. Nat. 2007, 169, E119-E140.

152. Cross, J.M.; von Korff, M.; Altmann, T.; Bartzetko, L.; Sulpice, R.; Gibon, Y.; Palacios, N.; Stitt, M. Variation of enzyme activities and metabolite levels in 24 Arabidopsis accessions growing in carbon-limited conditions. Plant Physiol. 2006, 142, 1574-1588.

153. Pigliucci, M.; Kolodynska, A. Phenotypic plasticity and integration in response to flooded conditions in natural accessions of Arabidopsis thaliana (L.) Heynh (Brassicaceae). Ann. Bot. (Lond) 2002, 90, 199-207.

154. Buckler, E.S.T.; Thornsberry, J.M. Plant molecular diversity and applications to genomics. Curr. Opin. Plant Biol. 2002, 5, 107-111.

155. Yu, J.; Buckler, E.S. Genetic association mapping and genome organization of maize. Curr. Opin. Biotechnol. 2006, 17, 155-160. 
156. Zhao, K.; Aranzana, M.J.; Kim, S.; Lister, C.; Shindo, C.; Tang, C.; Toomajian, C.; Zheng, H.; Dean, C.; Marjoram, P.; Nordborg, M. An Arabidopsis example of association mapping in structured samples. PLoS Genet. 2007, 3, e4.

157. Aranzana, M.J.; Kim, S.; Zhao, K.; Bakker, E.; Horton, M.; Jakob, K.; Lister, C.; Molitor, J.; Shindo, C.; Tang, C.; Toomajian, C.; Traw, B.; Zheng, H.; Bergelson, J.; Dean, C.; Marjoram, P.; Nordborg, M. Genome-wide association mapping in Arabidopsis identifies previously known flowering time and pathogen resistance genes. PLoS Genet. 2005, 1, e60.

158. Fu, J.; Keurentjes, J.J.; Bouwmeester, H.; America, T.; Verstappen, F.W.; Ward, J.L.; Beale, M.H.; de Vos, R.C.; Dijkstra, M.; Scheltema, R.A.; Johannes, F.; Koornneef, M.; Vreugdenhil, D.; Breitling, R.; Jansen, R.C. System-wide molecular evidence for phenotypic buffering in Arabidopsis. Nat. Genet. 2009, 41, 166-167.

(C) 2008 by the authors; licensee Molecular Diversity Preservation International, Basel, Switzerland. This article is an open-access article distributed under the terms and conditions of the Creative Commons Attribution license (http://creativecommons.org/licenses/by/3.0/). 